\title{
Sampling of the Diurnal Cycle of Precipitation using TRMM
}

\author{
Andrew J. Negri ${ }^{1}$, Thomas L. Bell ${ }^{1}$ and Liming $\mathrm{Xu}^{2}$ \\ ${ }^{1}$ Laboratory for Atmospheres, NASA/Goddard Space Flight Center, Greenbelt, MD \\ ${ }^{2}$ Dept. of Hydrology and Water Resources, U. Arizona, Tucson, AZ
}

Submitted to

The Journal of Atmospheric and Oceanic Technology

$12 / 01 / 01$ 


\begin{abstract}
We examine the temporal sampling of tropical regions using observations from the Tropical Rainfall Measuring Mission (TRMM) Microwave Imager (TMI) and Precipitation Radar (PR). We conclude that PR estimates at any one hour, even using three years of data, are inadequate to describe the diurnal cycle of precipitation over regions smaller than $12^{\circ}$, due to high spatial variability in sampling. We show that the optimum period of accumulation is four hours. Diurnal signatures display half as much sampling error when averaged over four hours of local time. A similar pattern of sampling variability is found in the TMI data, despite the TMI's wider swath and increased sampling. These results are verified using an orbital model. The sensitivity of the sampling to satellite altitude is presented, as well as sampling patterns at the new TRMM altitude of $402.5 \mathrm{~km}$.
\end{abstract}




\section{Introduction}

One of the priority science questions in the design of the Tropical Rainfall Measuring Mission (TRMM) was "What is the diurnal cycle of tropical rainfall and how does it vary in space?" (Simpson et al. 1988). Several studies have addressed the question of whether TRMM can provide enough observations at different local times to delineate the changes in average rainfall with time of day. Bell and Reid (1993) concluded that the TRMM Microwave Instrument (TMI) would be able to determine the first harmonic of the diurnal cycle in a $5^{\circ} \times 5^{\circ}$ grid box from one month of data to an accuracy of about $25 \%$ of the mean rain rate. This assumed rain with statistics like those of the rain data taken in the tropical Atlantic during GATE (Global-Atmospheric-Research-Program Atlantic Tropical Experiment). Imaoka and North (2000) used TMI rain rates binned to 1-h local times, combined with data from Special Sensor Microwave/Imager (SSM/I) instruments on the Defense Meteorological Satellite Program satellites, to deduce the diurnal cycle over large regions of the tropical oceans. They noted the limited number of TMI samples of the diurnal cycle available during one year (15 maximum) and the long interval between TRMM visits to a region at a given hour of the day and its next observation at a similar hour (23 days at the equator and 46 days at the highest latitudes accessible to TRMM). Lin et al. (2001) examined the impact of the diurnal cycle on monthly averages in a GCM simulation of the data collected by a satellite with TRMM's sampling pattern, and showed that the 46day cycle in local viewing times could cause monthly averages to exhibit spurious intraannual oscillations. Salby and Callaghan (1997), in a study of how different satellite orbits interact with diurnal sampling, have likewise emphasized that climatological studies using satellite data must be done with appropriate averaging of the data in order to minimize biases in the averages due to varying sample sizes at different times of the day.

No previous study has examined the coverage by TRMM of smaller regions as a function of local time, or made use of the PR data to do so. Moreover, no previous work has examined the particular pattern of spatial sampling generated by the interaction of 
TRMM's orbital period and swath width with the earth's rotation. In this study, we examine the temporal sampling of a tropical region, the Amazon Basin, using three years (1998-2000) of observations from both the TRMM TMI and Precipitation Radar (PR). We are motivated by the need to verify and interpret the estimates made by geosynchronous, infrared (IR) techniques, such as those described by Anagnostou et al. (1999) or Negri et al. (2001).

\section{Data}

The data used in this study come from a dataset designated 3G68. This dataset is processed at $0.5^{\circ}$ resolution globally and at $0.1^{\circ}$ resolution over Africa and South America. It contains gridded values of the total pixels (footprints), rainy pixels, mean rain rate and percentage of convective rain from the PR algorithm 2A25 and the TMI algorithm 2A12 (Kummerow et al. 2000).

\section{Results}

a. Sampling patterns

Figure 1 shows the results from three years (1998-2000) of PR (top) and TMI (bottom) sampling at one hour of local time $(00-01 \mathrm{LT})$ at the $0.5^{\circ}$ resolution of the $3 \mathrm{G} 68$ dataset. (The color scale was chosen to highlight tropical sampling at the expense of the higher latitudes). Note the absence of PR data over Australia due to intergovernmental agreement. Both sensors display a checkerboard pattern of hourly sampling at low latitudes, with the inhomogeneity more apparent in the PR sampling. We examine this pattern in detail for a representative tropical region, the Amazon Basin $\left(0-10^{\circ} \mathrm{S}, 75-50^{\circ} \mathrm{W}\right)$, denoted by the large white-outlined box in Fig. 1. Diurnal cycles of precipitation will be presented for all three outlined areas.

Figure 2 shows the PR orbital swaths over the Amazon Basin for one month (January, 2000) partitioned by local time. Each day of the month is displayed in a separate color. 
Periods of low coverage (e.g., 11-16 LT, in which only descending orbits are present) alternate with periods of higher coverage (e.g., 18-22 LT). At a height of $350 \mathrm{~km}$, the ascending orbit will revisit an area at approximately the same local time about every 46 days. Figures 3 and 4 display, respectively the hourly PR and TMI sampling at $0.1^{\circ}$ resolution for one year (2000). The number of PR samples ranges from zero to 10, with a mean of five. It is apparent that neighboring $5^{\circ} \times 5^{\circ}$ areas experience quite different sampling, and that several small regions receive no coverage at certain hours. The sampling pattern repeats over a four-hour period, as is evident by scanning vertically down any column of plotted data. This phenomenon turns out to be intrinsic to a satellite orbiting at this altitude, and will be discussed later. The TMI sampling (Fig. 4) has the same checkerboard pattern as the PR, but with greater sample numbers due the wider TMI swath. The number of observations ranges from 8 to 23 with a mean of 15 .

In Figure 5, we explore PR sampling accumulated for periods from 1 to $6 \mathrm{~h}$ (plotted vertically) and for one year (2000) and three years (1998-2000) (plotted horizontally). The parameter sigma/mean mapped in Fig. 5 is the standard deviation (s) divided by the mean (m) of the $250 \times 1000.1^{\circ}$ resolution grid cells in each scene. This ratio attempts to quantify the homogeneity of each scene, with lower numbers indicating more uniform sampling. It is evident that four-hour accumulations provide the most spatially even sampling pattern across this region. (Note that the color scale changes from plot to plot.) Adding two more years of data, while tripling the sampling, does not appreciably smooth the pattern at any accumulation period. Further accumulation using 5-7 hours increases the unevenness of the sampling pattern. Figure 6 shows the results of accumulating the TMI data in the same fashion. Despite the increased sampling, the pattern is the same as the PR, and again varies least for accumulations of four hours. The expected poleward increase in TRMM sampling is particularly evident in the 3-year patterns, especially for 4-hour accumulation times, when the pattern is smoothest. 
We conclude that to eliminate hourly variations in the sampling pattern requires the accumulation (or averaging) over four hours of local time. We next demonstrate the effect of these patterns on the estimation of the diurnal cycle of precipitation.

\section{b. Diurnal cycles of precipitation}

In Figures 7-9, we show the diurnal cycle of precipitation for the three boxes delineated in Fig.1. Figure 7 shows the results for a $5^{\circ} \times 5^{\circ}$ area over land $\left(5-10^{\circ} \mathrm{S}, 65-70^{\circ} \mathrm{W}\right)$ using three years (1998-2000) of TRMM observations. Mean hourly values are displayed on the left, while 4-hour running mean rain rate is shown on the right, for both the PR (top) and TMI (bottom). The sampling errors $( \pm \sigma / \sqrt{ } \mathrm{n})$ are plotted as vertical lines. The PR, and to some extent the TMI, display variations on hourly time scales due to the inconsistent sampling of this small area. The sampling errors tend to be proportional to the magnitude of the mean rain rate. The errors in the hourly means range from 15 to $48 \%$ for the PR and from 13 to $34 \%$ for the TMI. Accumulating both the rain and the sampling over a 4-h period centered on each hour produced the smoother graphs on the right. The sampling errors become more consistent from hour-to-hour, ranging from $8-22 \%$ for the PR and 7$17 \%$ for TMI, about a factor of two reduction. Over land, the TMI estimates tend to be higher than the PR (Adler et al 2001) and we find this to be true here, with about a $20 \%$ high bias by the TMI. Both estimates show a maximum at $16 \mathrm{LT}$.

The obscuration of the diurnal cycle is more apparent for an oceanic grid box of same size and sampling. Figure 8 shows the results for such a box, located at $5-10^{\circ} \mathrm{N}, 30-35^{\circ}$ $\mathrm{W}$. The sampling errors for the hourly PR rain rate range from 20 to $65 \%$, while values for the TMI estimates range from 18 to $28 \%$. Smoothing over a 4-h period highlights the weak morning rainfall maximum at $6 \mathrm{LT}$. Sampling errors are reduced to $13-23 \%$ for the PR and $10-13 \%$ for the TMI. Note the good agreement between the PR and TMI over an oceanic area. 
The above sampling problems are clearly maximized at scales of about $5^{\circ}$. It will be shown in the next section that this is to be expected from a satellite at an altitude of $350 \mathrm{~km}$ with a swath width as narrow as that of the PR. The orbital model predicts the sampling to rise and fall every $11.6^{\circ}$, with 31 cycles around the globe. This is in fact what we find in the global observations of Fig. 1.

To give one practical example of the implications of this phenomenon, we examine the usefulness of the TRMM estimates as validation for infrared-based satellite rain estimates over large regions. One such scheme is the Convective-Stratiform Technique (Adler and Negri, 1988) recently recalibrated with TMI data over the Amazon Basin (Negri et al. 2001). Figure 9 is a plot of one year of these estimates over the region $0-10^{\circ} \mathrm{S}$ and $50-75^{\circ} \mathrm{W}$. The unsmoothed PR estimates (top left) show variations on hourly time scales even for this rather large region. The sampling errors range from 9 to $27 \%$ of the mean. This is reduced by half $(5-11 \%)$ when smoothed over $4 \mathrm{~h}$, and the $16 \mathrm{LT}$ rain maximum in the CST is verified. Like most infrared techniques, the CST tends to underestimate the lighter morning rainfall and overestimates the afternoon maximum. The TMI estimates seem sufficiently sampled over this region to permit the use of the raw hourly mean rain rates.

\section{Diurnal sampling versus satellite altitude}

The diurnal sampling patterns explored in the previous sections are due to TRMM's orbit. This issue has not generally arisen with other earth-observing satellites because most satellites are placed in either near-sun-synchronous polar orbits with orbital inclinations of about $98^{\circ}$, or geosynchronous orbits with inclination $0^{\circ}$. Sun-synchronous satellites view spots on the earth at two specified local times $12 \mathrm{~h}$ apart and are unable to see the entire diurnal cycle by design. Geosynchronous satellites are capable of viewing a sector of the earth continuously, at least in principle. TRMM was placed in a low-inclination orbit both to improve the sampling of tropical latitudes and to enable it to visit points on the earth at many different local times. As is evident from the above discussion, analysis of TRMM 
data must take careful account of the interaction of the sampling pattern with the diurnal cycle.

In this section, we use a simple orbital model to explore how diurnal sampling depends on satellite altitude. The model helps bring out some underlying characteristics of the sampling patterns seen above and can help anticipate the kinds of problems that may need to be addressed in using the data provided by TRMM in its higher orbit.

The orbit model is based on the equations for satellite orbits reviewed by Brooks (1977). A brief description of the equations used here can also be found in the appendix of the paper by Shin and North (1988). In this model, the satellite describes a circular orbit in a plane that precesses slowly over the course of a year due to the earth's equatorial bulge. It ignores higher-order asymmetries in the earth's gravitational field and other gravitational influences, and does not include the effects of atmospheric drag nor the occasional orbital adjustments using the satellite's onboard thrusters. It is nevertheless remarkably accurate in predicting the behavior of satellites like TRMM.

Much of the sampling behavior of a satellite can be understood knowing just two characteristics of the satellite's orbit: the time it takes to orbit the earth once and the longitudinal shift with each orbit. More precisely, the nodal period $\tau_{N}$ is defined as the time it takes for the satellite to go from one equatorial crossing, moving northward (the ascending node), to the next; and the longitudinal shift $\Delta \lambda_{N}$ is the change in longitude from ascending node to ascending node. For TRMM, with its $35^{\circ}$ inclination orbit and at its original altitude of $350.0 \mathrm{~km}, \tau_{N} \approx 91 \mathrm{~min}$ and $\Delta \lambda_{N} \approx-23.3^{\circ}$. Most of the longitudinal shift is a consequence of the rotation of the earth during the $1.5 \mathrm{~h}$ taken by the satellite to go once around and return to the equator. A small additional amount is caused by the precession of the orbital plane. The change in local time at the equator from orbit to orbit is given by

$$
\Delta \mathrm{LT}=\tau_{N}+\Delta \lambda_{N} /\left(15^{\circ} / \mathrm{h}\right)
$$

which, for TRMM, is about $-0.033 \mathrm{~h}$. In other words, the local time at each equatorial 
crossing is earlier by $0.033 \mathrm{~h}$. The satellite requires about 732 orbits ( 46.4 days) before it crosses the equator (ascending) at the same local time. It should be noted that the local times for the descending node and the ascending node are separated by approximately $12 \mathrm{~h}$. Consequently, the ascending and descending branches of the orbit together can cover the entire diurnal cycle near the equator in about 23 days.

Suppose the satellite crosses the equator at longitude $0^{\circ}$ at local time 1200 , and we plot local times and longitudes of successive equatorial crossings. Figure 10 shows such a plot for a period of one year, with the first 100 crossings distinguished by open circles. The crossings tend to occur at certain hours of the day only at certain longitudes, and to fall along equally spaced diagonal lines. Depending on the swath width of the instrument, this can result in gaps in coverage. In the particular case shown in Fig. 10, the pattern starts to break down after many months of orbiting. Very small changes in satellite altitude can radically alter the pattern. This can be understood by considering the effect on $\Delta \lambda_{N}$ of increasing the altitude by just $1 \mathrm{~km}$. For a $1-\mathrm{km}$ increase, the westward shift $\Delta \lambda_{N}$ is calculated from the orbit model to increase by $-0.0050^{\circ}$. In the 732 orbits it took to return to the same local time at the original altitude, this small change in $\Delta \lambda_{N}$ results in a shift in the longitudinal position by $732 \times\left(-0.0050^{\circ}\right)=-3.6^{\circ}$. Thus, if an altitude is found where the ascending node occurs at nearly the same local time and longitude as approximately 732 orbits before, a change of only a fraction of $1 \mathrm{~km}$ will produce a significant change in the situation and destroy the repeat cycle.

To illustrate this sensitivity further, we show in Fig. 11 the sampling density predicted by the orbital model, plotted analogously to the earlier figures, for an orbital altitude of $350.0 \mathrm{~km}$. Figure 12 shows the corresponding sampling density for an altitude of 349.7 $\mathrm{km}$. A decrease of only $0.3 \mathrm{~km}$ results in a completely different sampling pattern.

The pattern seen in Fig. 10 suggests that there might be altitudes where the crossing locations fall exactly on diagonal lines. In such a case, the pattern would be characterized by three integers $p, q$, and $s$ defined as follows: the diagonal lines intersect the horizontal 
axis in a plot like Fig. $10 q$ times and have dimensionless slope $s / q$, intersecting the vertical axis IsI times; and the longitudinal shift of the satellite $\Delta \lambda_{N}$ with each orbit causes it to jump from one diagonal line to the $p$ th neighboring line. This means that for a specified triplet of integers $p, q, s$, an altitude must be found for which the longitudinal shift and period satisfy the equation

$$
\frac{\Delta \lambda_{N}}{360^{\circ}}=\frac{p}{q}+\frac{s}{q} \frac{\Delta \mathrm{LT}}{24 \mathrm{~h}}
$$

where $\Delta \mathrm{LT}$ is given by Eq. (4.1). Examination of Fig. 10 suggests that the pattern of diagonal lines is very nearly described by the integers $p=-2, q=31$, and $s=6$. Indeed, using Mathematica (Wolfram 1996), we find that Eq. (4.2) is satisfied for these integers for an altitude $a=350.107 \mathrm{~km}$, which is very close to the nominal altitude of TRMM for the time period 12/97 - 8/01. The fact that the repeat pattern in Fig. 10 is characterized by $s=6$ explains why averaging the data over $4 \mathrm{~h}$ produces uniform sampling at all longitudes, since the pattern repeats 6 times in 24 hours.

To get a more general view of how the diurnal sampling changes with satellite altitude, the orbital model was again used. We wish to know how much time it would take an instrument like the PR, which scans side to side over an angle of about $34.8^{\circ}$, to see every point near the equator at least once during each hour of local time, as a function of the altitude of the satellite. To simplify the calculation, rather than compute the time required for full coverage, we instead compute the time required for the PR to observe every point along the equator between two swaths that have just been viewed by the PR in successive ascending orbits. The observations filling in this gap, in order to count, are required to fall within a half-hour (local time) of the time of the original swaths that define the observational gap. The time to fill in the gap between two successive ascending orbits, though not quite as easy to interpret as the time for full coverage, is probably representative of the amount of time involved in obtaining full coverage. It is an approximate lower limit for the time. 
Figure 13 shows this "diurnal coverage time" for the TRMM PR for a range of altitudes within $5 \mathrm{~km}$ of TRMM's original altitude. As discussed earlier, the coverage changes rapidly with altitude. Some of the spikes in coverage time are identified by the three integers defining the repeat pattern, based on solutions to Eq. (4.2). It should be noted that these results depend on the swath width of the satellite instrument. The TMI, for instance, would show better coverage with fewer spikes.

The TRMM satellite was moved to a higher orbit in August 2001 in order to conserve fuel and thereby extend its life. The choice of altitude required a number of compromises, many of them dictated by proper functioning of the radar. TRMM is presently operating at an altitude of $402.5 \mathrm{~km}$. At its new altitude TRMM will revisit an area at approximately the same local time every 47.5 days instead of the 46.4 days it previously required. Figure 14 shows a plot of diurnal coverage time for altitudes around this new operating altitude and Fig. 15 shows the sampling density predicted by the orbital model. In reality, the TRMM satellite is constrained to altitudes $402.5 \pm 1.5 \mathrm{~km}$, so we would expect the observed sampling pattern to be slightly different.

\section{Conclusions}

In this study, we have examined the temporal sampling of the Amazon Basin using observations from the TRMM Microwave Imager and Precipitation Radar. We conclude that the PR estimates at any one hour, even using three years of data, are inadequate to describe the diurnal cycle of precipitation at scales less than $12^{\circ}$, due to spatially inconsistent sampling. We show that the optimum period of accumulation is four hours to minimize the potentially large variations in sampling error due to this pattern. Resultant diurnal signatures display less "noise" when averaged over four hours of local time, and the sampling errors were reduced by a factor of two. The same pattern is true of the TMI, despite its wider swath and increased sampling. Results of this experiment were verified using an orbital model, and the sensitivity of the sampling to satellite altitude was presented. 
A change as small as $300 \mathrm{~m}$ results in dramatic differences in the sampling pattern at one hour of local time. Sampling patterns at the new TRMM altitude of $402.5 \mathrm{~km}$ were also calculated and displayed. These results have important implications for picking the orbits of future satellites, such as those contemplated by the Global Precipitation Mission.

Acknowledgments. The authors thank Steve Bilanow for his insight into orbital mechanics, and to Dr. Matt McGill for his expertise in IDL programming. The authors acknowledge the continued support of Dr. Ramesh Kakar, NASA/HQ TRMM Program Manager. 


\section{REFERENCES}

Adler, R.F. and A.J.Negri, 1988: A satellite infrared technique to estimate tropical convective and stratiform rainfall. J. Appl. Meteor., 27, 30-51.

Adler, R.F., C. Kummerow, D. Bolvin, S. Curtis, C. Kidd, 2001. Status of TRMM Monthly Estimates of Tropical Precipitation, Meteorological Monographs, Symposium on Cloud Systems, Hurricanes and TRMM, (accepted).

Anagnostou, E.N., A.J. Negri, and R.F. Adler, 1999: A satellite infrared technique for diurnal rainfall variability studies. J. Geophys. Res., 104, 31,477-31,488.

Bell, T.L. and N. Reid, 1993: Detecting the diurnal cycle of rainfall using satellite observations. J. Appl. Meteor., 32, 311-322.

Brooks, D. R., 1977: An introduction to orbit dynamics and its application to satellite-based earth monitoring missions, NASA Ref. Pub. 1009, National Technical Information Service, Springfield, VA, 84 pp.

Imaoka, K. and R.W. Spencer, 2000: Diurnal variation of precipitation over the tropical oceans observed by TRMM/TMI combined with SSM/I. J. Climate, 13, 4149-4158.

Kummerow, C.D. et al. (24 co-authors), 2000: The status of the Tropical Rainfall Measuring Mission (TRMM) after two years in orbit. J. Appl. Meteor., 39, 19651982.

Lin, X., L. D. Fowler, and D. a. Randall, 2001: Flying the TRMM satellite in a GCM. J. Geophys. Res., in press.

Negri, A.J., L. Xu, and R.F. Adler, 2001: A TRMM-Calibrated Infrared Rainfall Algorithm Applied Over Brazil. J. Geophys. Res. (in press).

Shin, K.-S., and G. R. North, 1988: Sampling error study for rainfall estimate by satellite using a stochastic model. J. Appl. Meteor., 27, 1218-1231. 
Salby, M. L., and P. Callaghan, 1997: Sampling error in climate properties derived from satellite measurements: Consequences of undersampled diurnal variability. J. Climate, 10, 18-36.

Simpson, J., R.F. Adler and G. R. North, 1988: A proposed Tropical Rainfall Measuring Mission (TRMM) satellite. Bull. Amer. Meteor. Soc., 69, 278-295.

Wolfram, S., 1996: The Mathematica Book, $3^{\text {rd }}$ Ed. Wolfram Media, Cambridge University Press, 1427 pp. 


\section{Figure Captions}

Fig. 1. Sampling by the TRMM PR (top) and TMI (bottom) at 00-01 LT for the three-year period 1998-2000. Spatial resolution is $0.5^{\circ}$. The color scale was designed to highlight tropical sampling at the expense of the high latitudes. White-outlined boxes delineate areas of study in later figures.

Fig. 2. Sampling by the TRMM PR for January 2000, stratified by local time. Each day's orbits are plotted in a different color.

Fig. 3. Sampling of the Amazon Basin by the TRMM Precipitation Radar for 2000 , stratified by local time. Spatial resolution is $0.1^{\circ}$.

Fig. 4. As in Fig. 3 but for TRMM Microwave Imager sampling.

Fig. 5. PR sampling at $0.1^{\circ}$ resolution for accumulation periods of $1,2,4$ and 6 hours. Left column is for 2000; right column is for 1998-2000. The parameter sigma/mean denotes the ratio of the standard deviation of the 250 by 100 points to the mean, a measure of the inhomogeneity of the pattern.

Fig. 6. As in Fig. 6 but for TMI sampling.

Fig. 7. Diurnal cycle of precipitation over a $5^{\circ} \times 5^{\circ}$ box centered at $7.5^{\circ} \mathrm{S}, 67.5^{\circ} \mathrm{W}$ in the Amazon Basin. Left: Mean hourly values for the PR (top) and TMI (bottom); Right: values smoothed over a 4-h running mean. Three years of data from 1998-2000 were used.

Fig. 8. Same as Fig. 7 except for an oceanic grid box centered at $7.5^{\circ} \mathrm{N}, 32.5^{\circ} \mathrm{W}$.

Fig. 9. Same as Fig. 7 except for a $25^{\circ}$ by $10^{\circ}$ box over the Amazon Basin. Data from 2000 were used. Also plotted on each graph are the estimates from the infrared-based CST/TMI (Negri et al. 2001). 
Fig. 10. Local equatorial crossing time versus longitude for ascending nodes of a simulated TRMM orbit. The satellite is allowed to orbit for one year. Crossings for the first 100 orbits are indicated by open circles. The remaining crossings are indicated by dots. The first crossing, at local time 1200 and longitude $0^{\circ}$, is indicated with an arrow.

Fig. 11. TRMM PR sampling derived from an orbital model using an altitude of $350 \mathrm{~km}$.

Fig. 12. As in Fig. 11, but using an altitude of $349.7 \mathrm{~km}$.

Fig. 13. An estimate of the time required for points near the equator to be seen at least once at every hour of local time. The observational swath is assumed to be like that of the TRMM PR, and the range of altitudes is within $5 \mathrm{~km}$ of the original nominal altitude of TRMM, $350 \mathrm{~km}$ (indicated by arrow). Spikes in the diurnal coverage time are labeled by the three integers $(p, q, s)$ in Eq. (4.2) characterizing the repeat pattern associated with that altitude.

Fig. 14. As in Fig. 13 but using an altitude of within 5 km of TRMM's new (8/15/01) altitude of $402.5 \mathrm{~km}$ (indicated by arrow).

Fig. 15. As in Fig. 11, but using an altitude of $402.5 \mathrm{~km}$. 
PR sampling $1998-2000$ at 1 hour LT

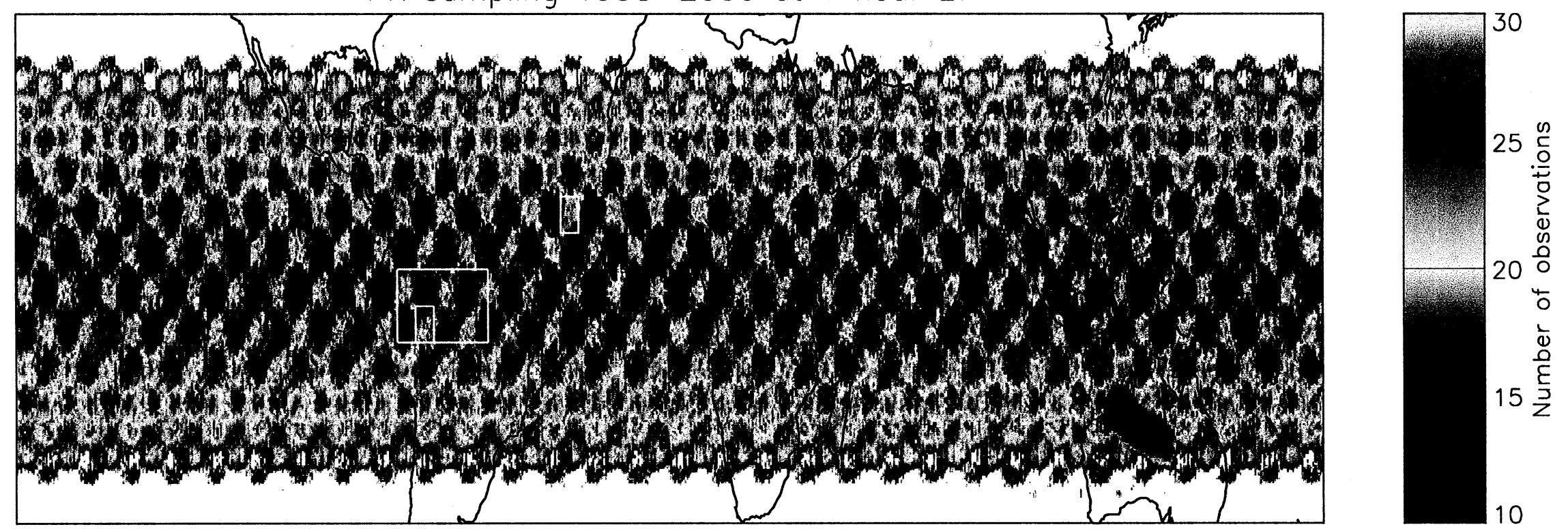

TMI sampling 1998-2000 at 1 hour LT
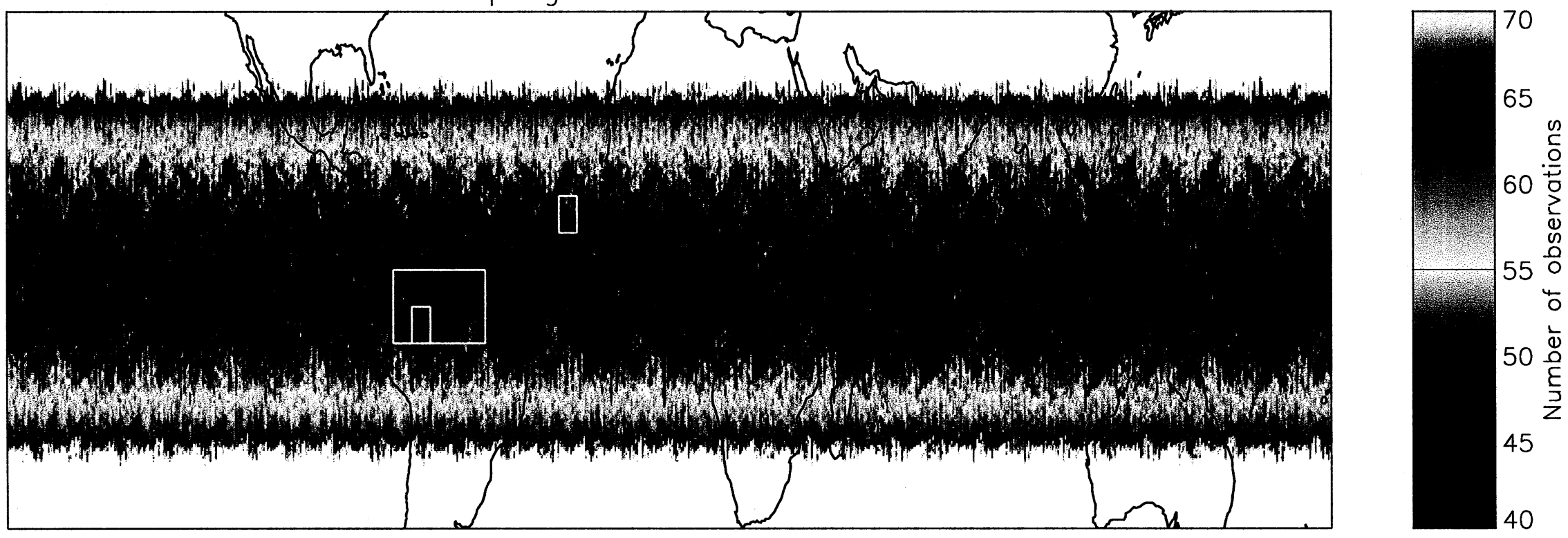


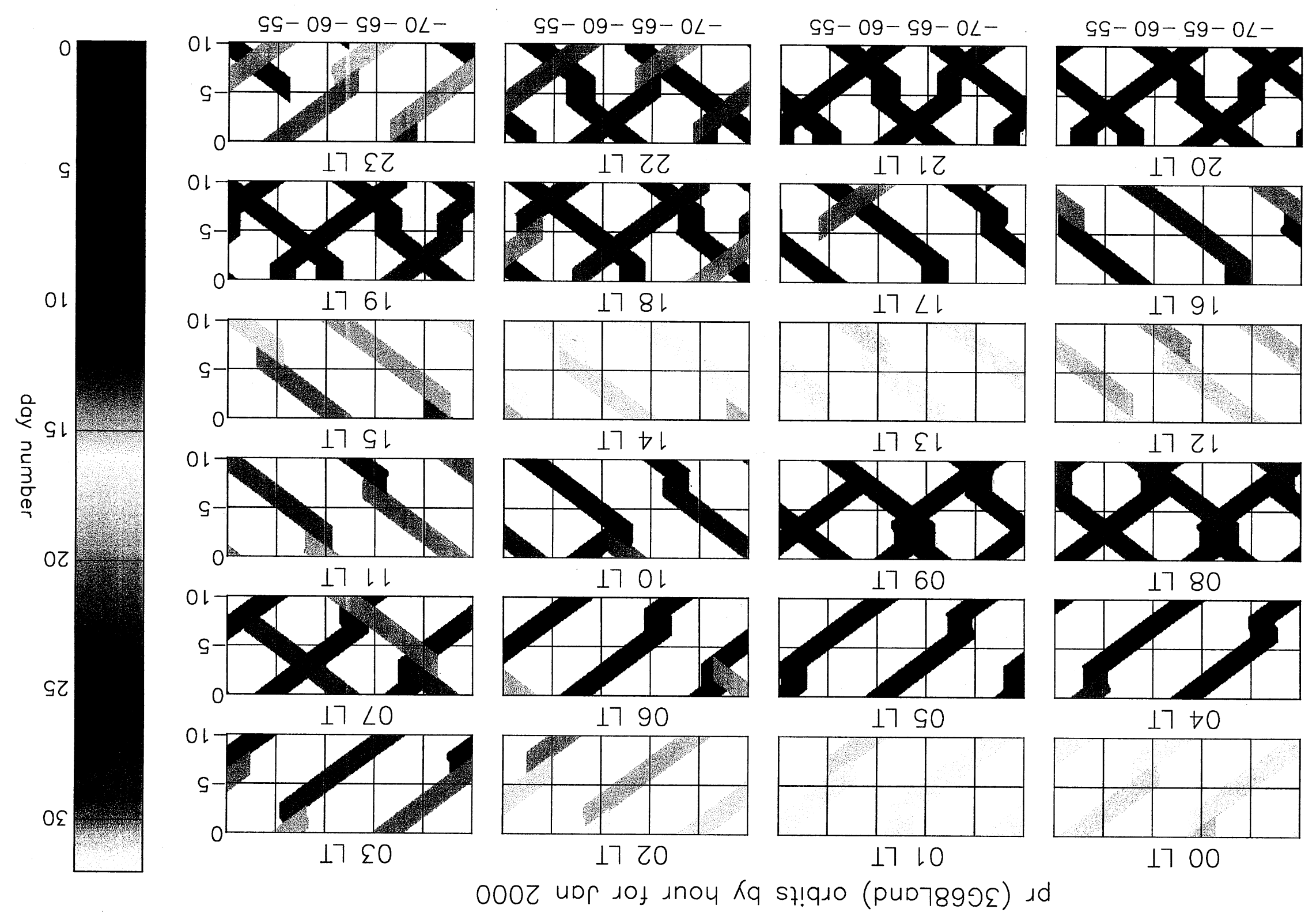


PR (3G68Land) observations by hour for 2000
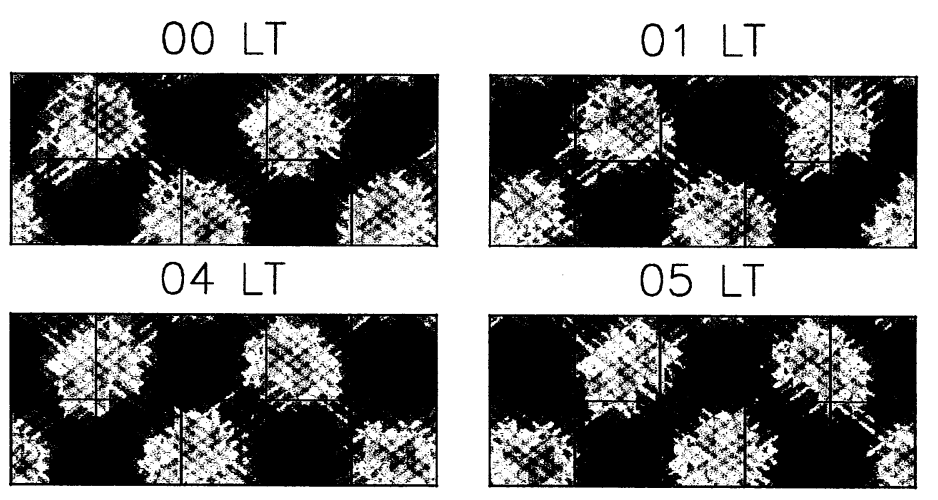

08 LT

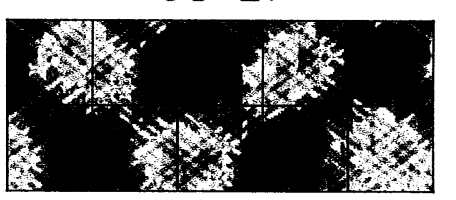

12 LT

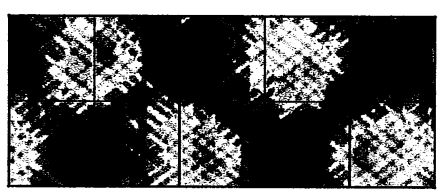

$16 \mathrm{LT}$

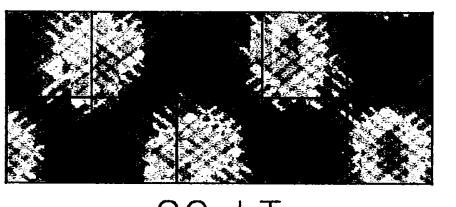

$20 \mathrm{LT}$
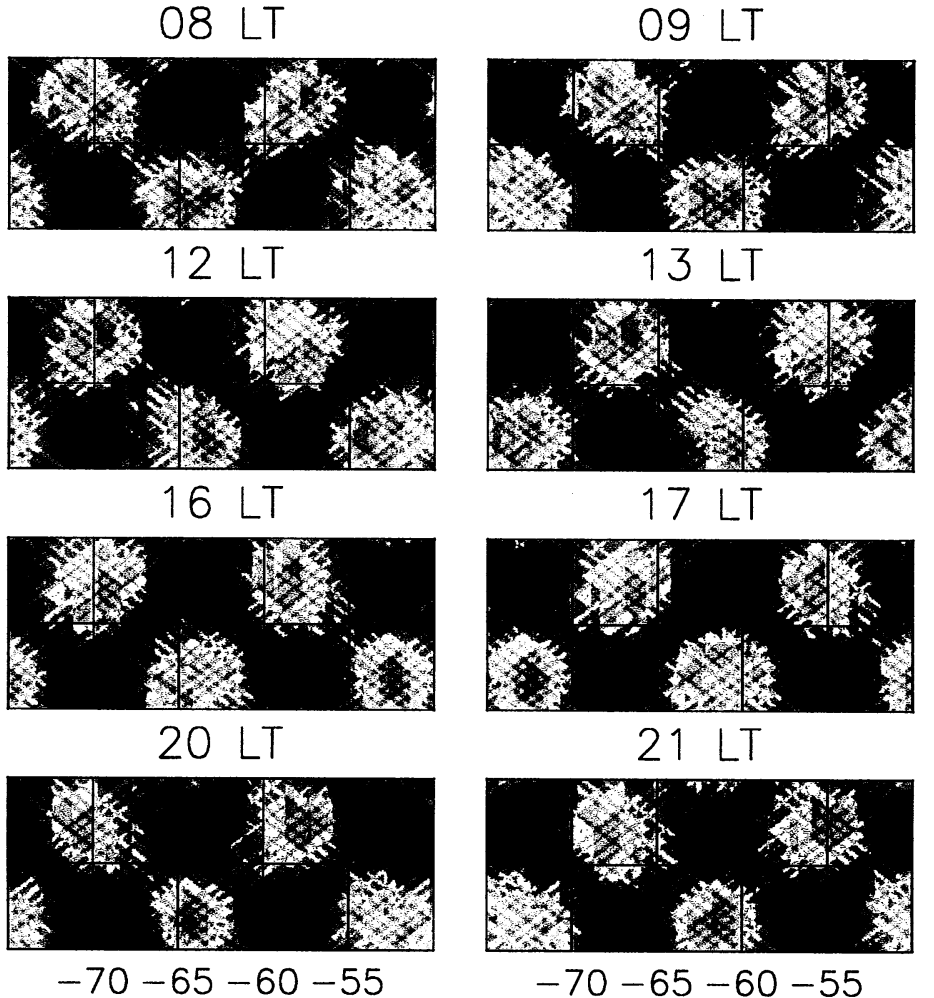

$13 \mathrm{LT}$

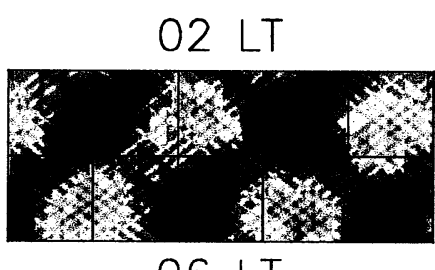

06 LT

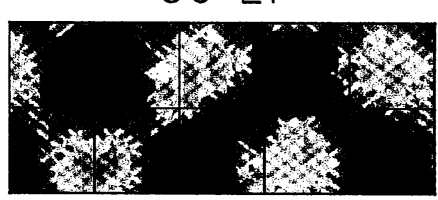

$10 \mathrm{LT}$

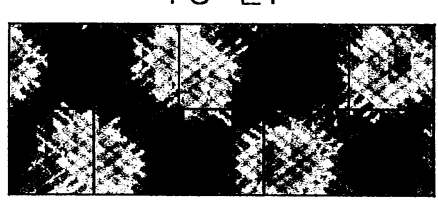

$14 \mathrm{LT}$
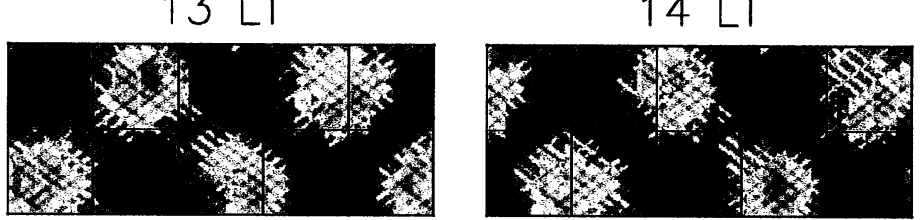

18 LT

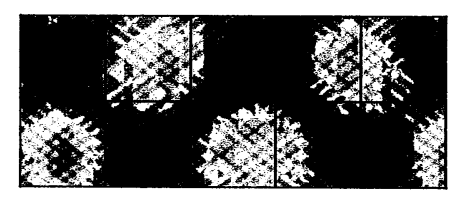

$21 \mathrm{LT}$
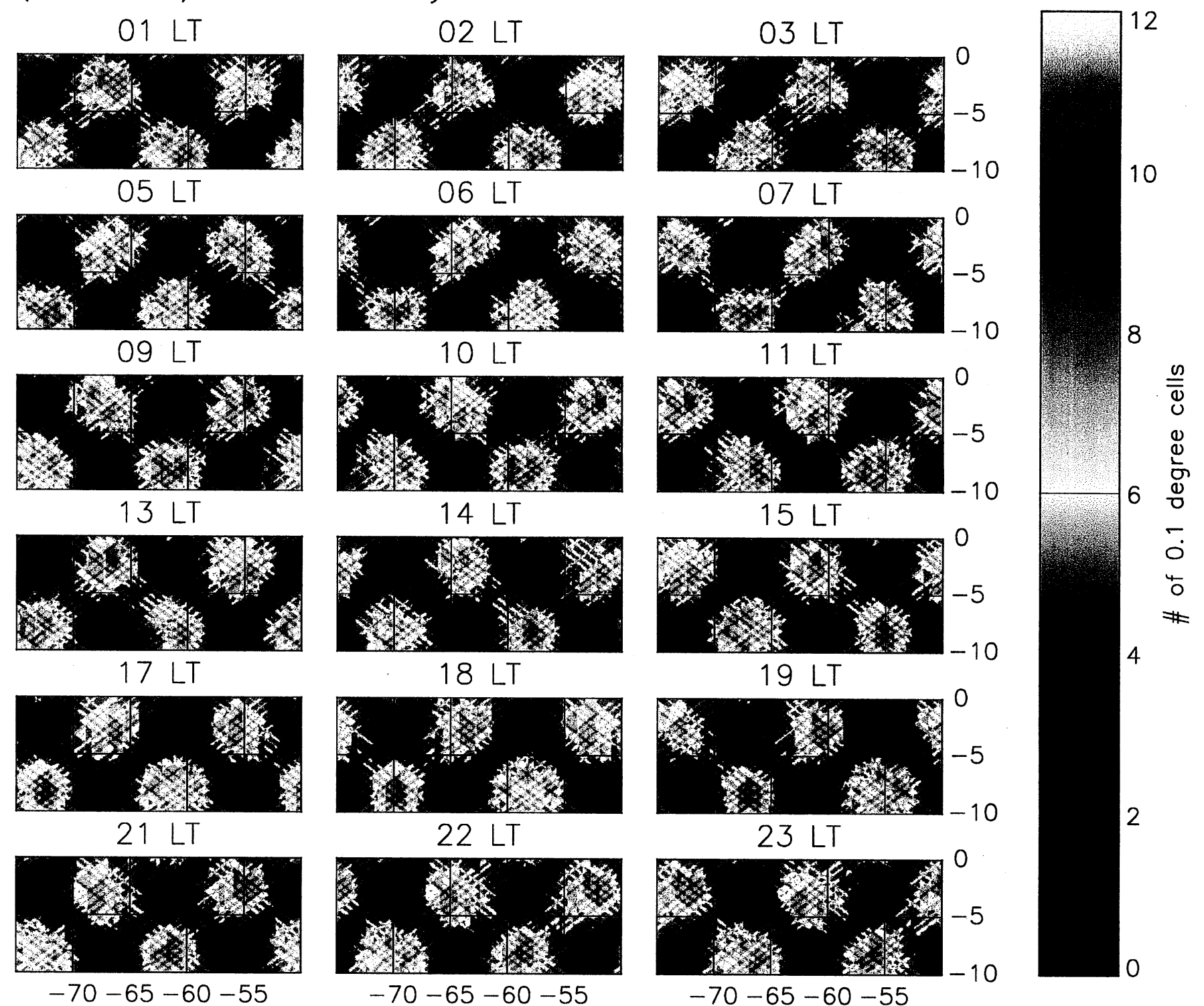
TMI (3G68Land) observations by hour for 2000

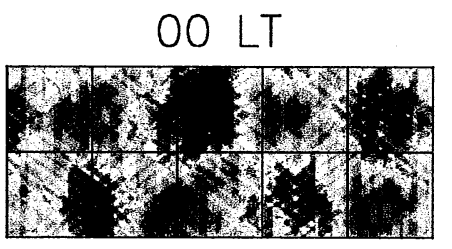

04 LT

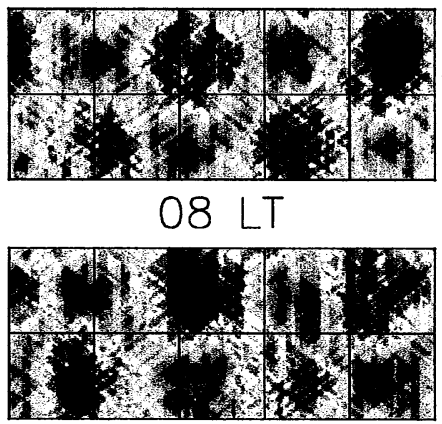

$12 \mathrm{LT}$

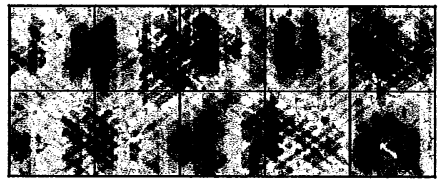

$16 \mathrm{LT}$

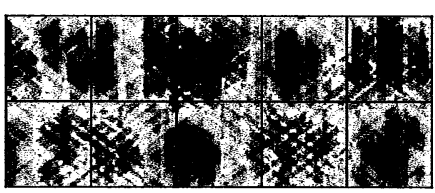

20 LT

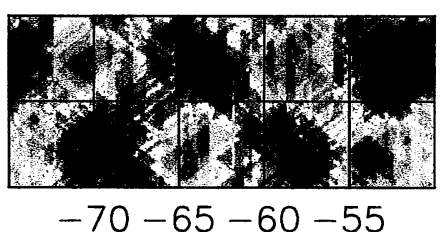

01 LT

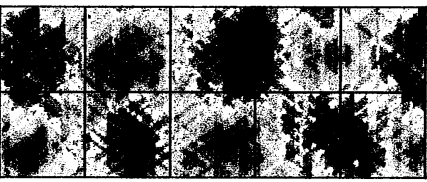

05 LT

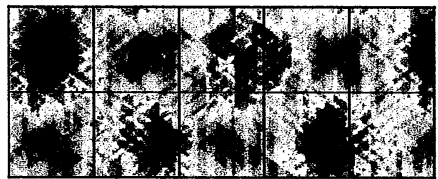

09 LT

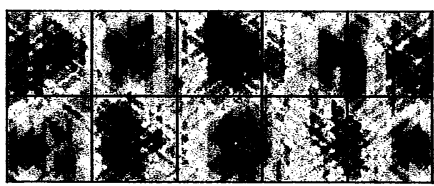

13 LT

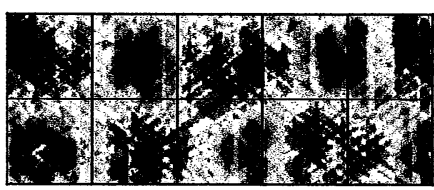

$17 \mathrm{LT}$

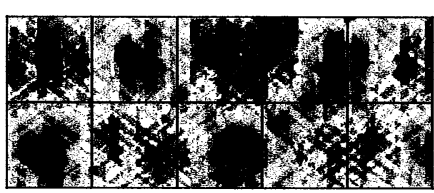

$21 \mathrm{LT}$

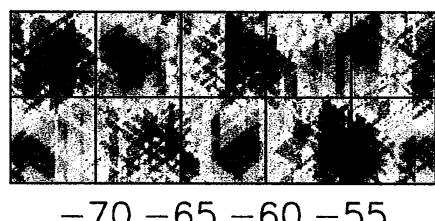

02 LT

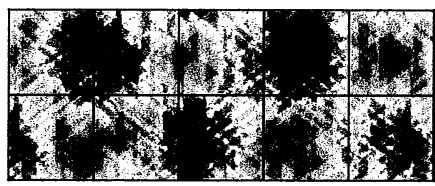

06 LT

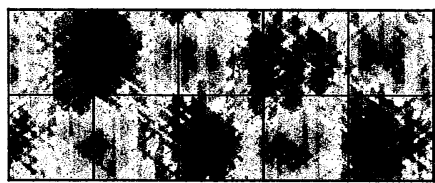

$10 \mathrm{LT}$

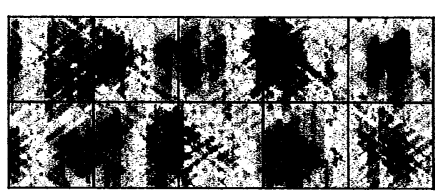

14 LT

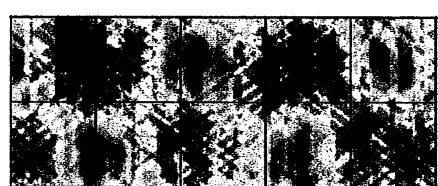
$18 L T$

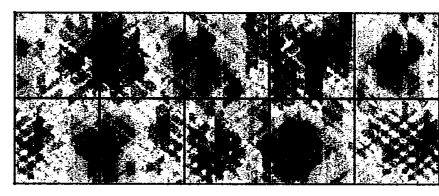

22 LT

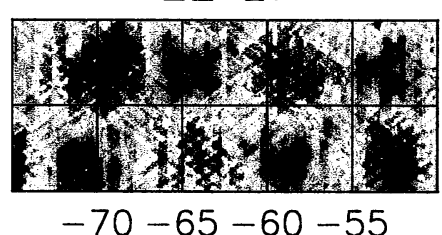

$03 \mathrm{LT}$

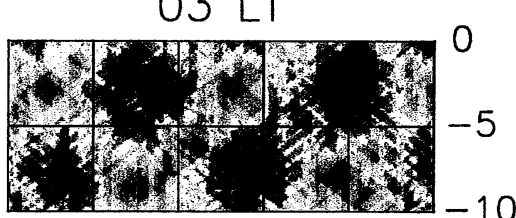

07 LT

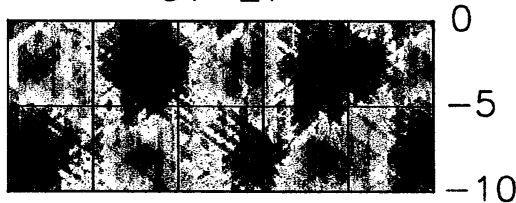

$11 \mathrm{LT}$

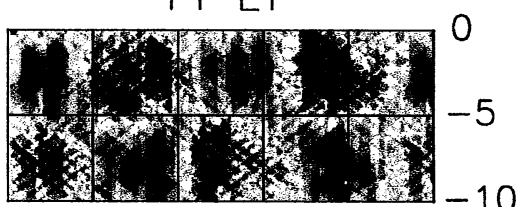

$15 \mathrm{LT}$

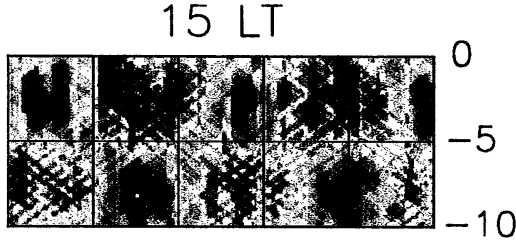

19 LT
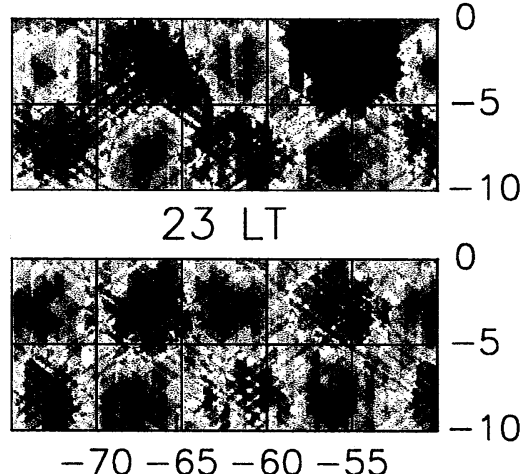

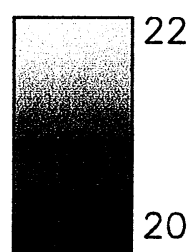

18

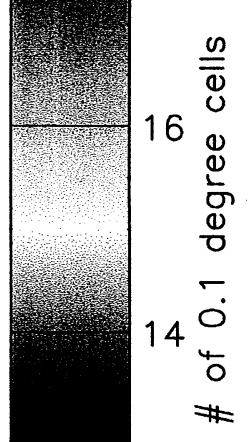

12

10 

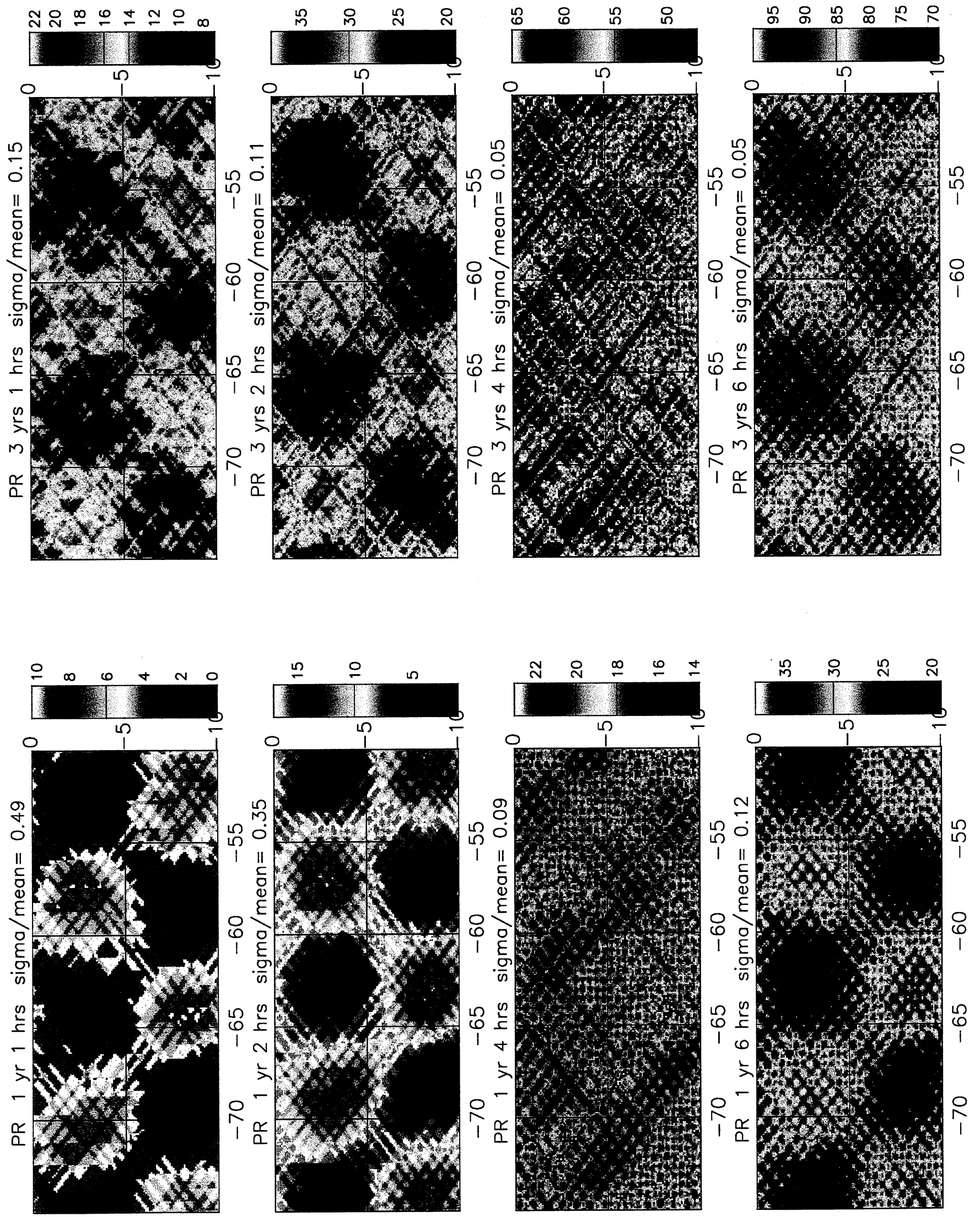
TMI 1 yr $1 \mathrm{hrs}$ sigma $/$ mean $=0.14$

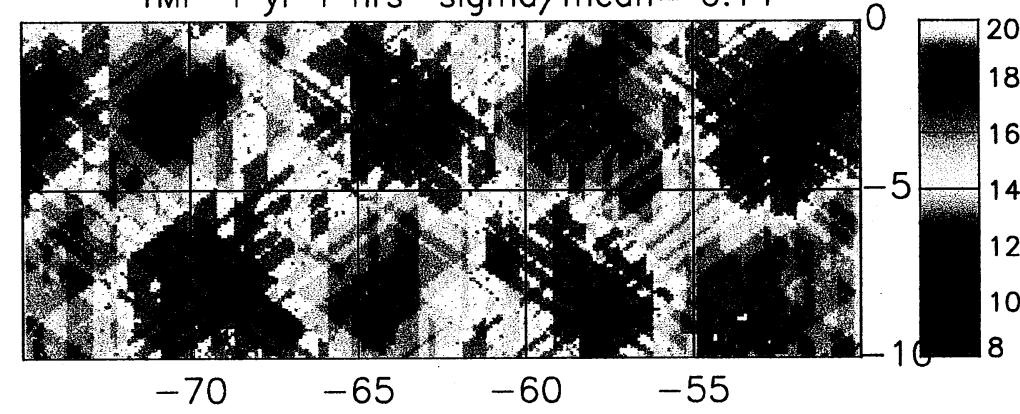

TMI 1 yr $2 \mathrm{hrs}$ sigma $/$ mean $=0.09$

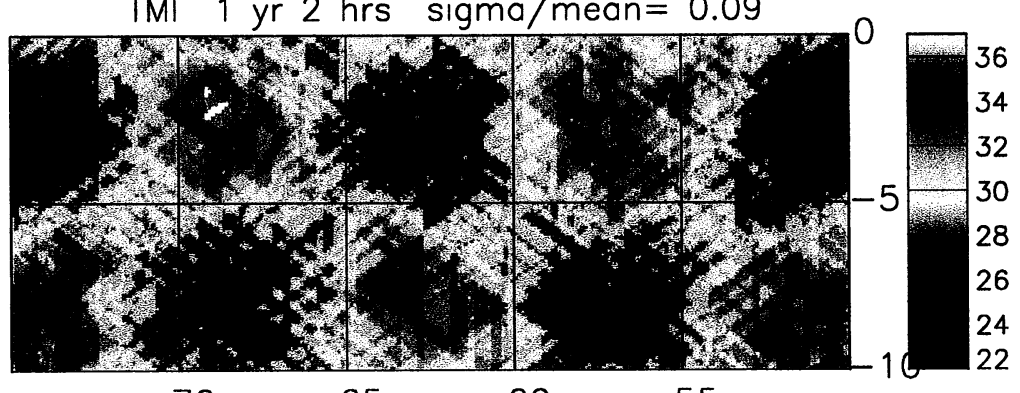

$-70$

$-65$

$-60$

$-55$

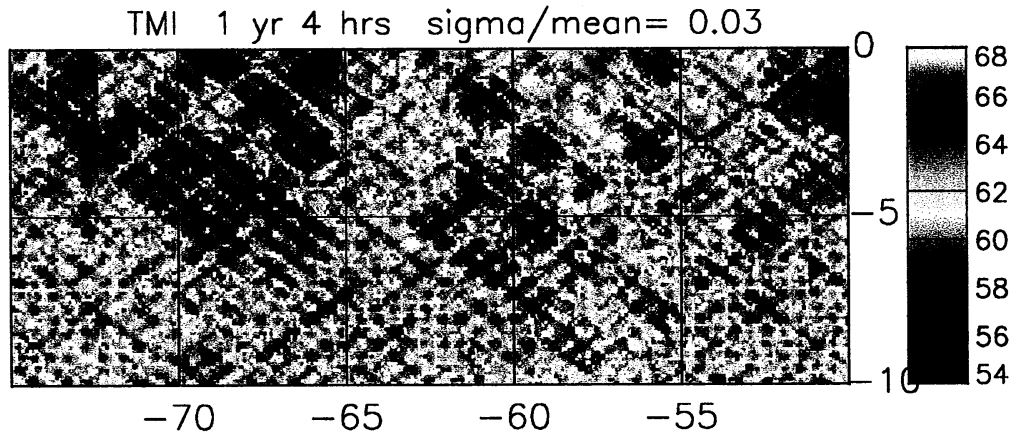

$$
\begin{array}{llll}
-70 & -65 & -60 & -55
\end{array}
$$

TMI 1 yr $6 \mathrm{hrs}$ sigma $/$ mean $=0.04$

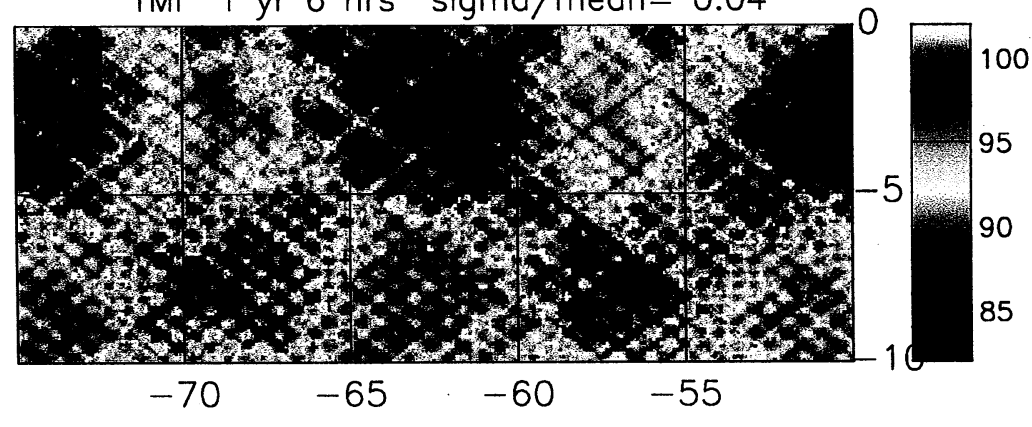

TMI 3 yrs $1 \mathrm{hrs}$ sigma $/$ mean $=0.05$

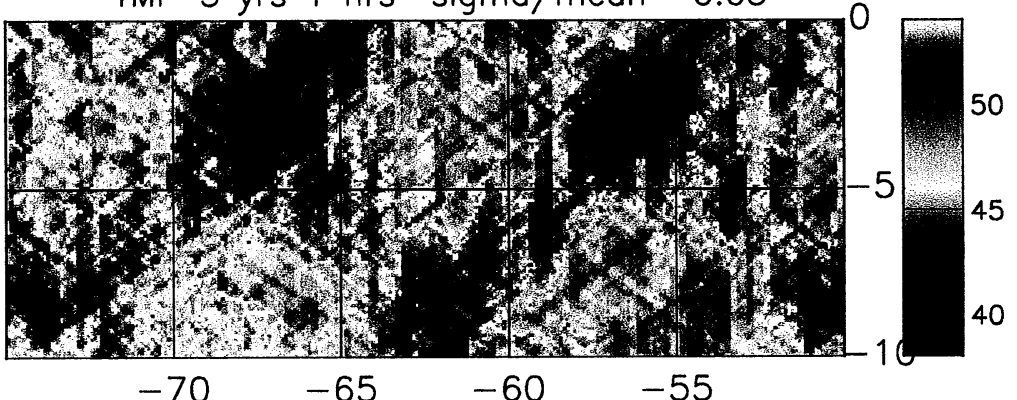

$\begin{array}{llll}-70 & -65 & -60 & -55\end{array}$

TMI 3 yrs $2 \mathrm{hrs}$ sigma $/$ mean $=0.03$

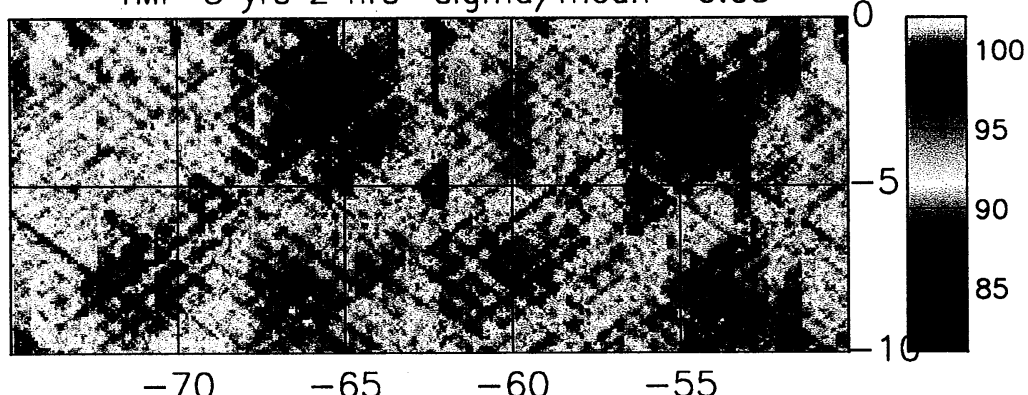

$\begin{array}{llll}-70 & -65 & -60 & -55\end{array}$

TMI 3 yrs $4 \mathrm{hrs}$ sigma $/$ mean $=0.02$

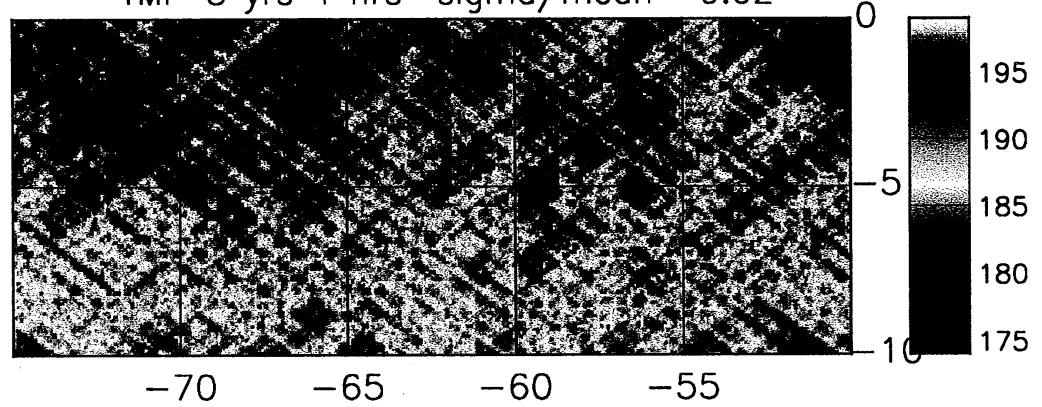

TMI 3 yrs $6 \mathrm{hrs}$ sigma $/$ mean $=0.02$

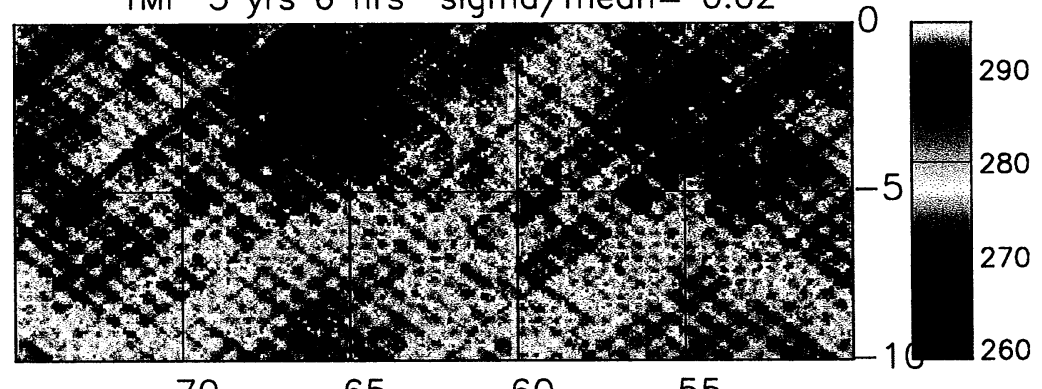

$\begin{array}{llll}-70 & -65 & -60 & -55\end{array}$ 

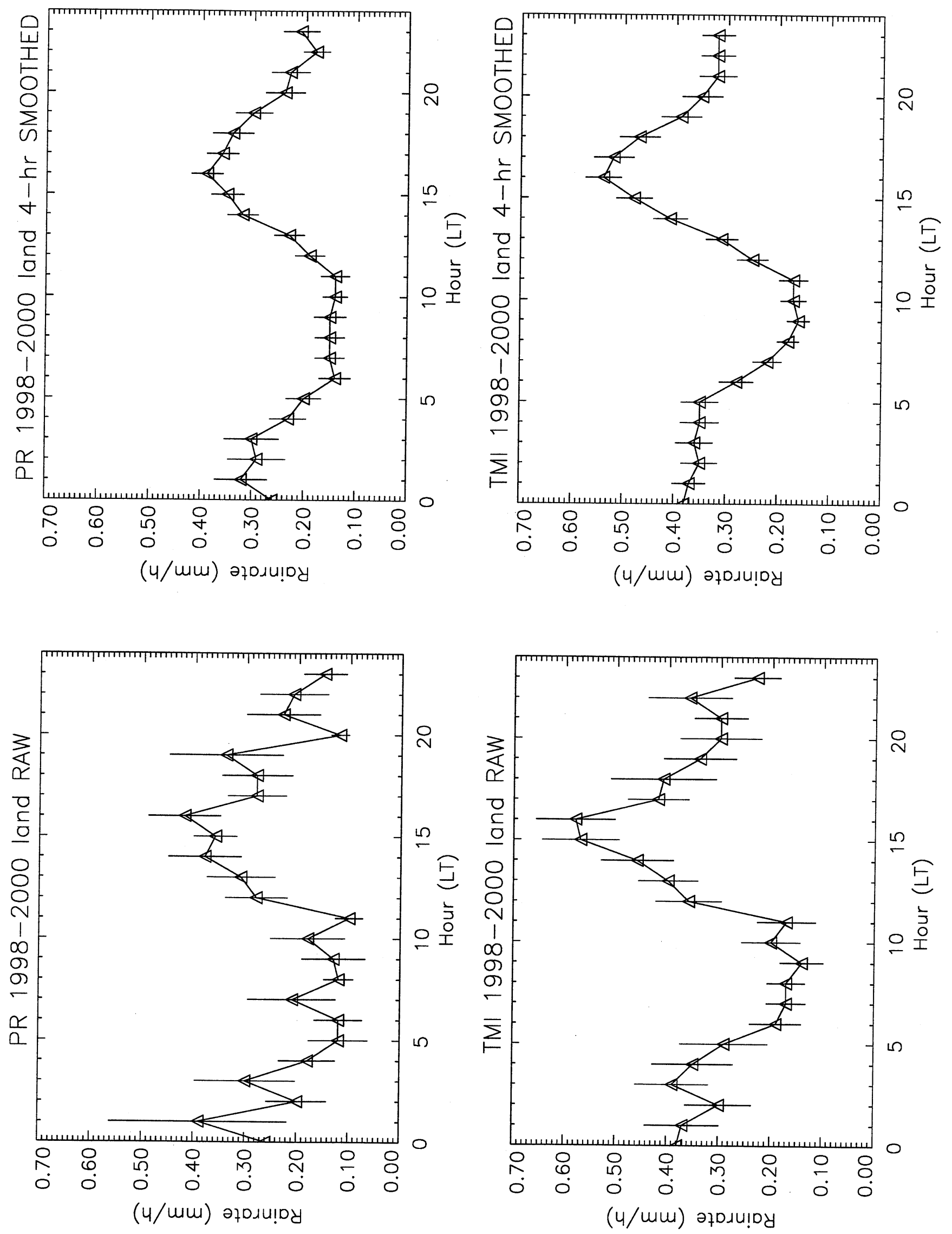

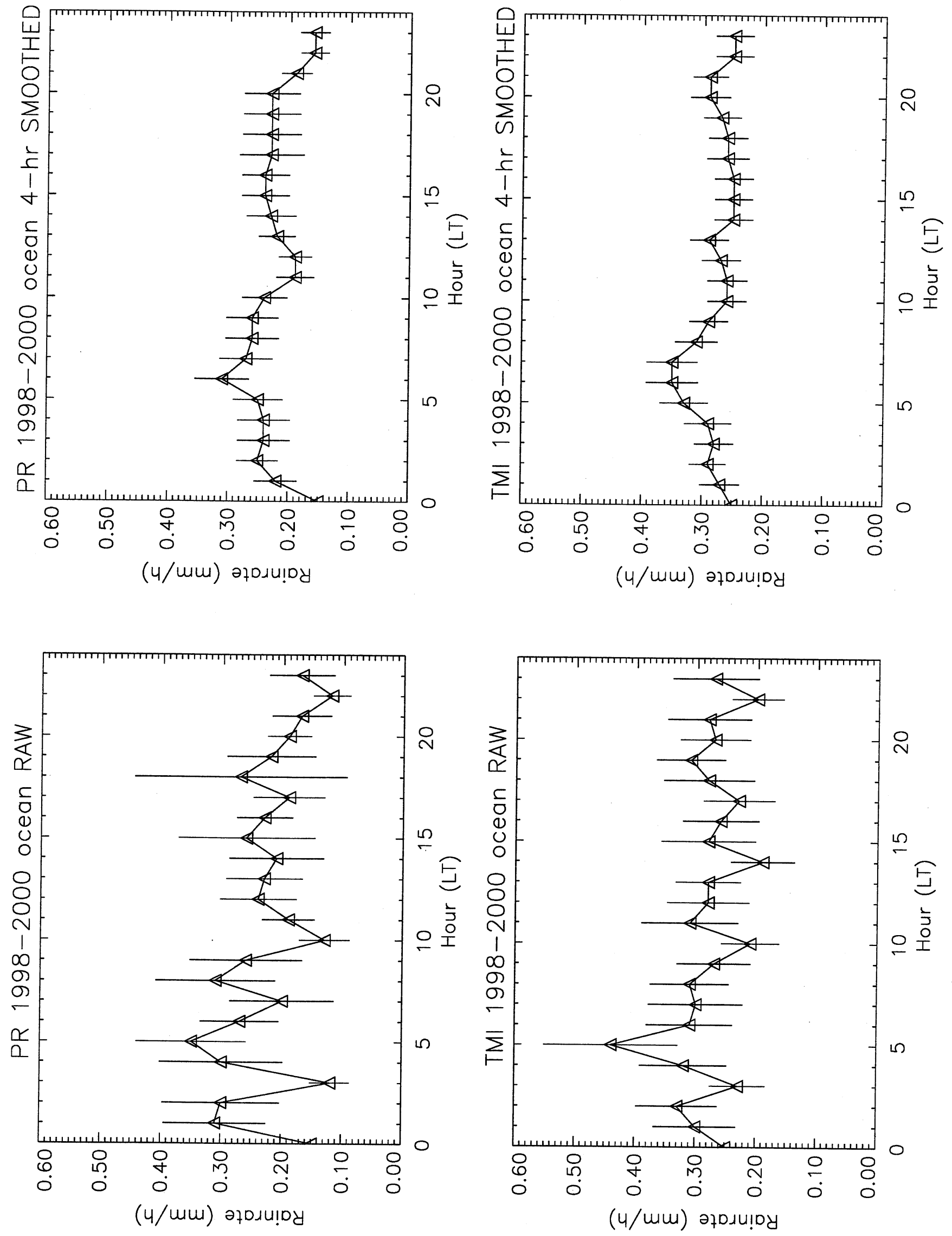


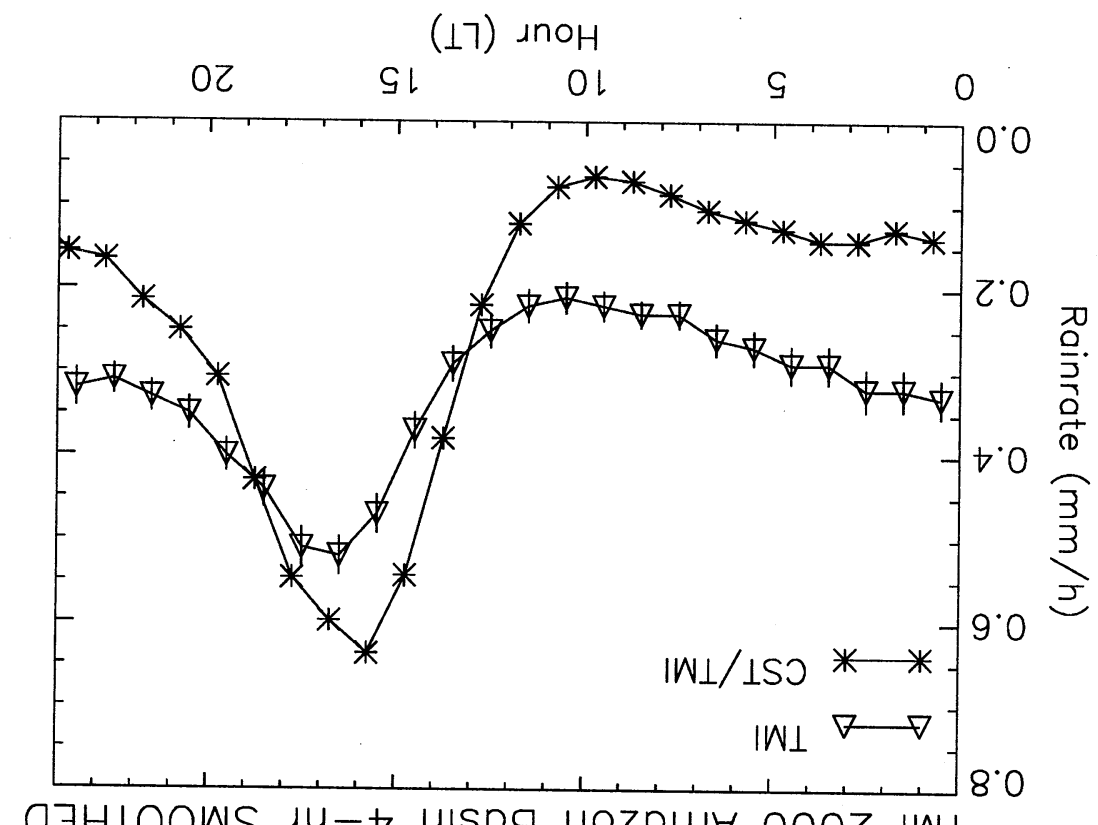

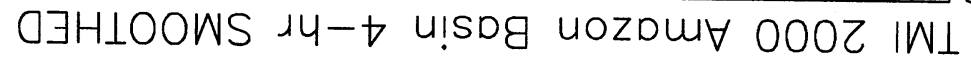

(17) $\mathrm{\Perp noH}$

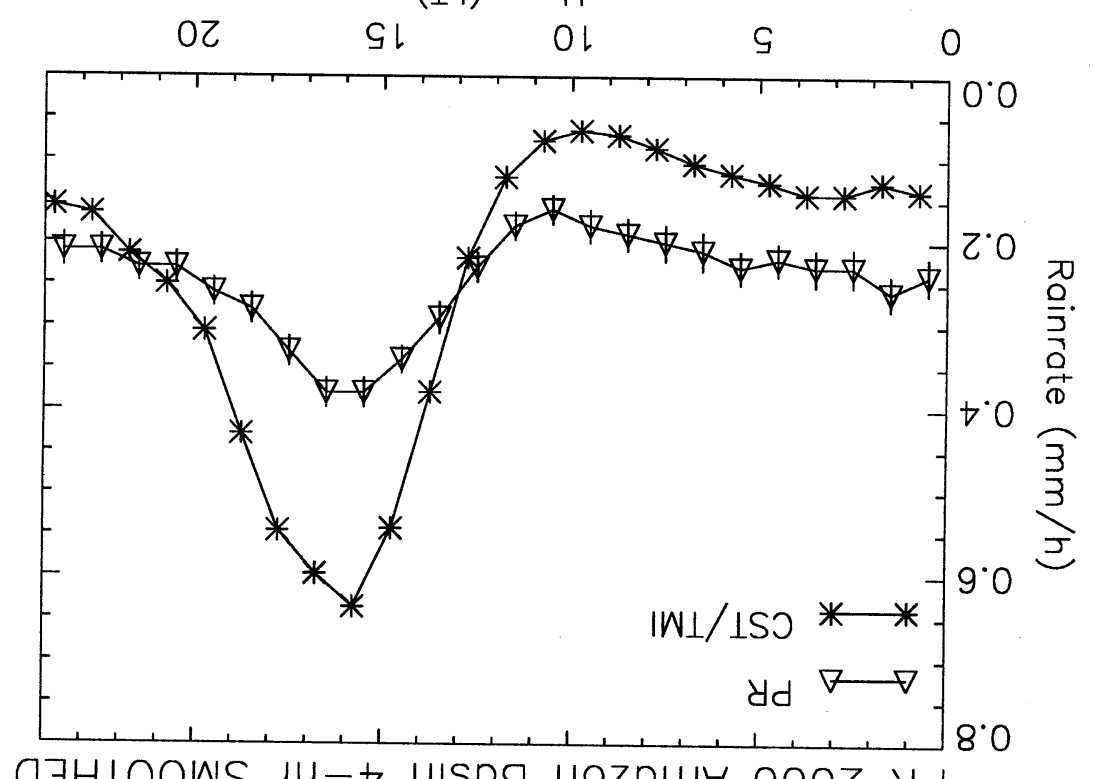

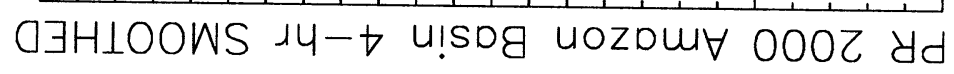
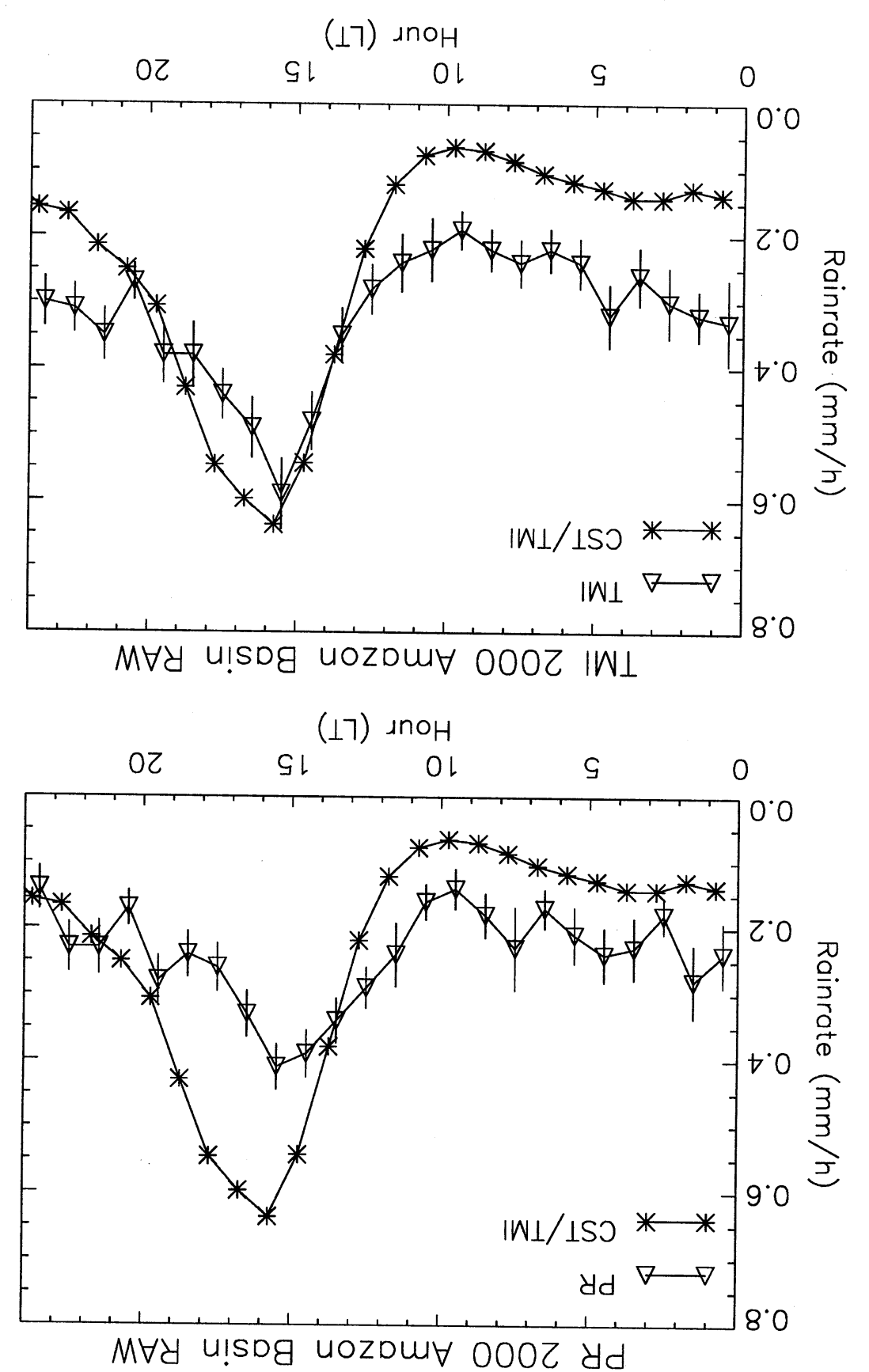


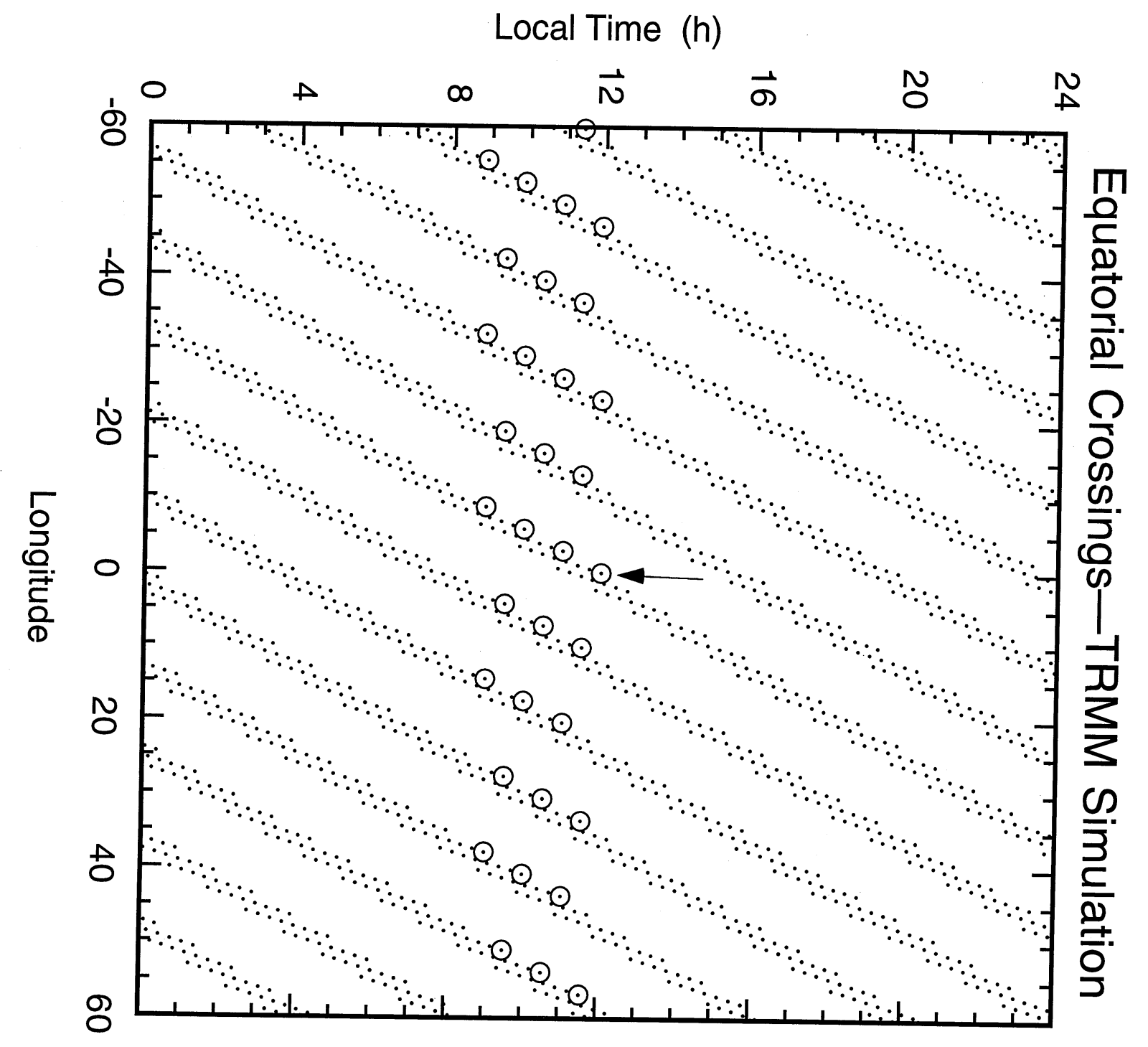




\section{suo!fD^dəsqo to dəqunN}

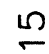

ค

○
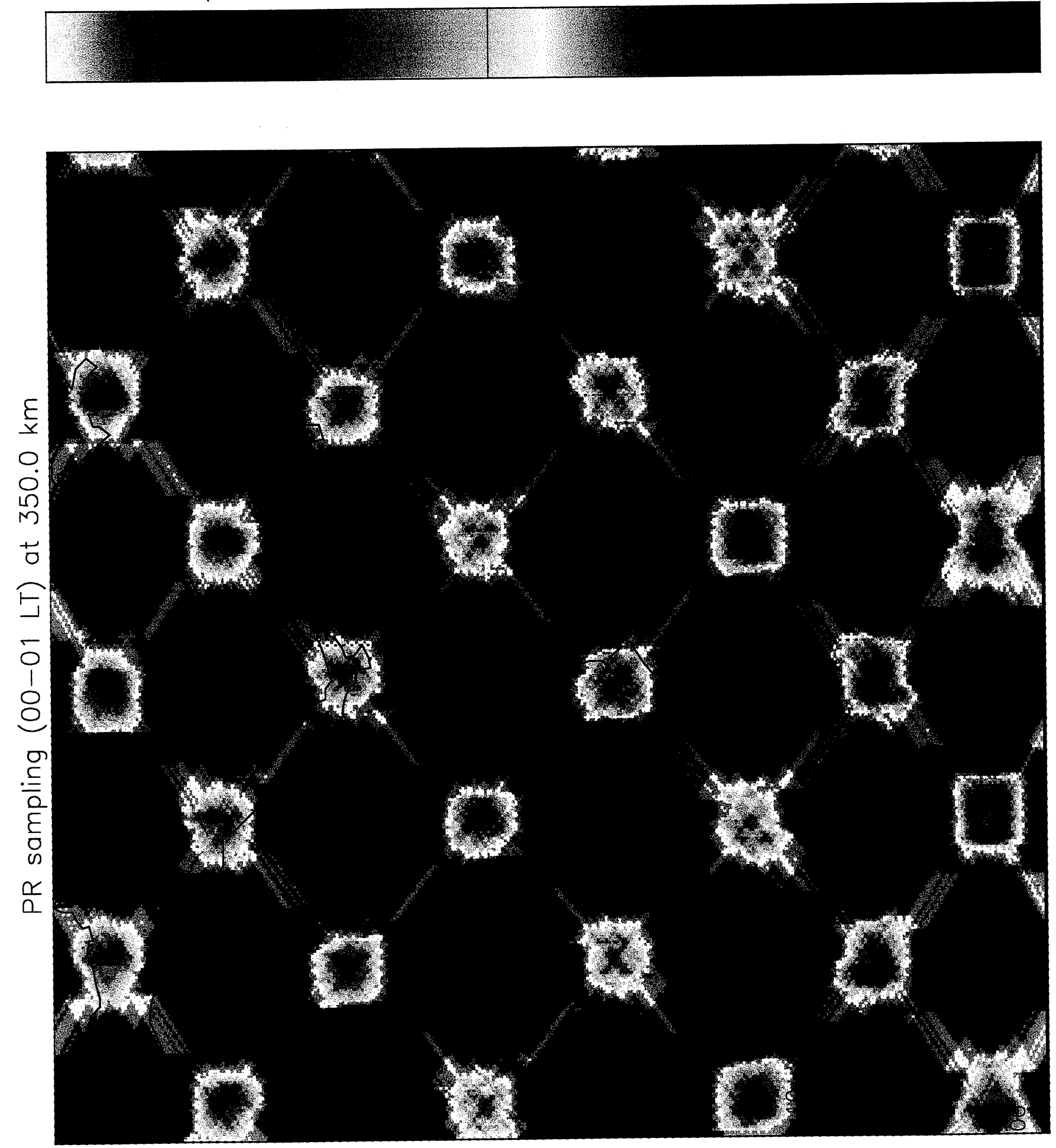
suo! 0 jəsqo to dəqunN

은

$\infty$

0

$\forall$

N

0

(2)

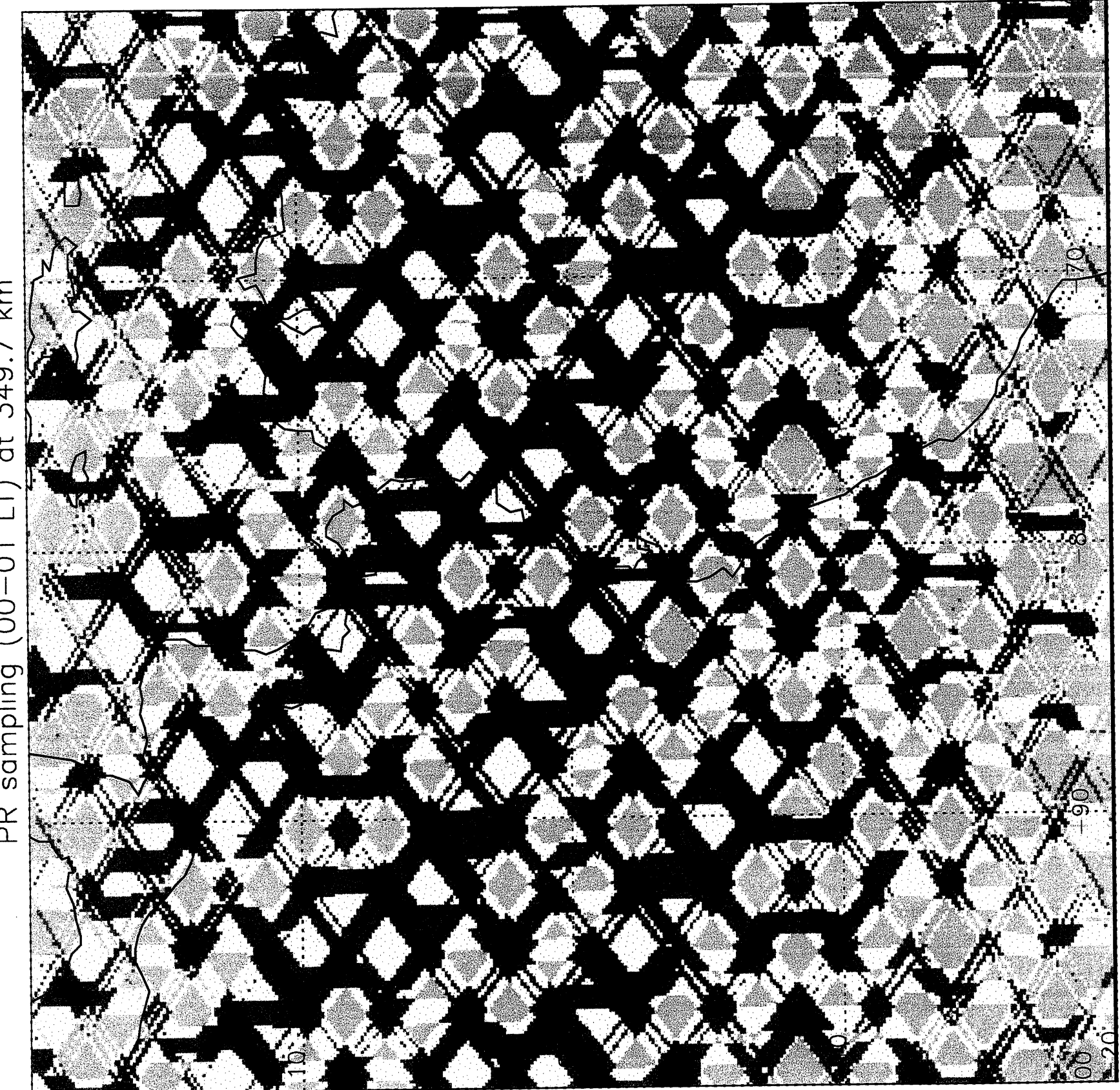




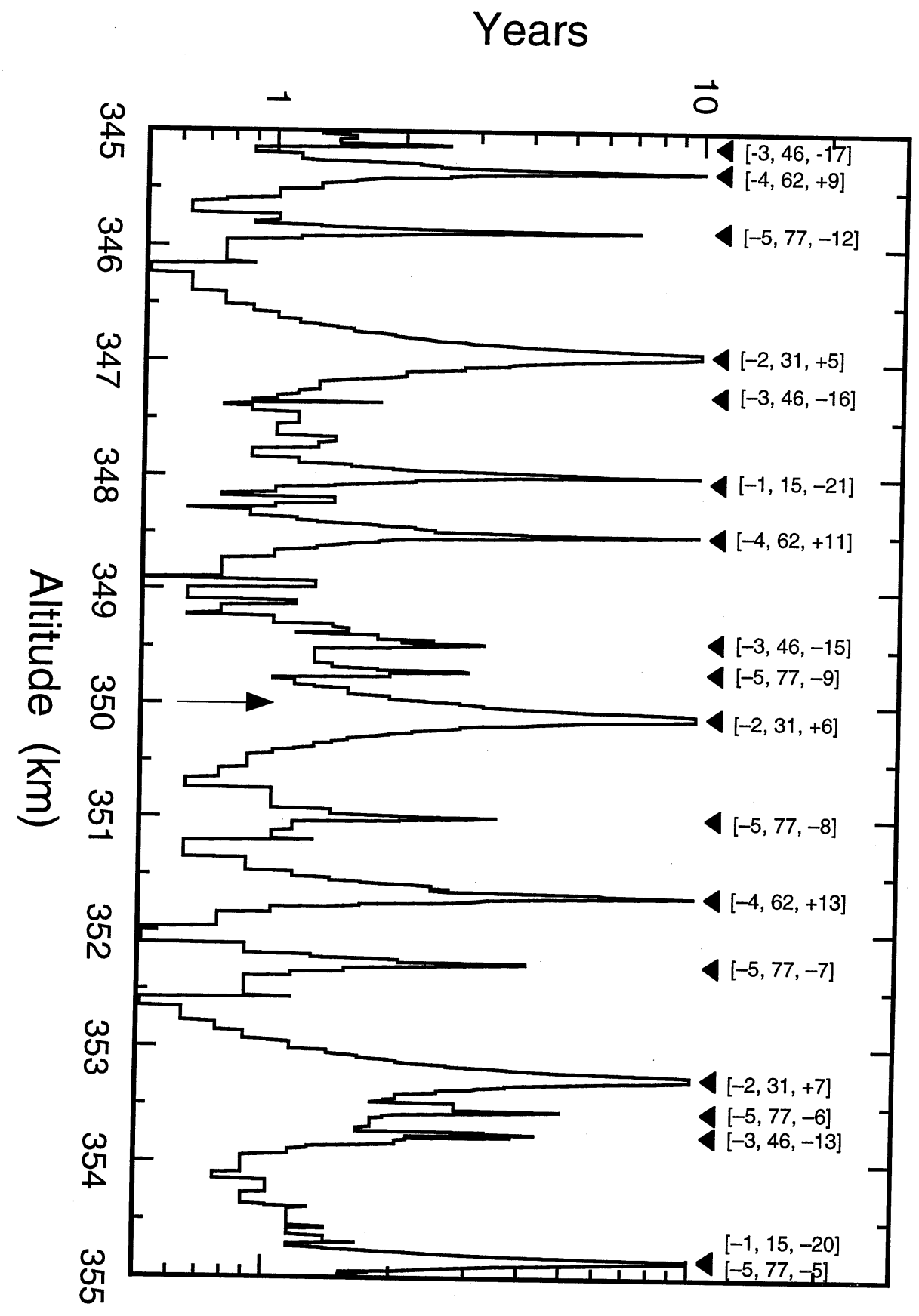




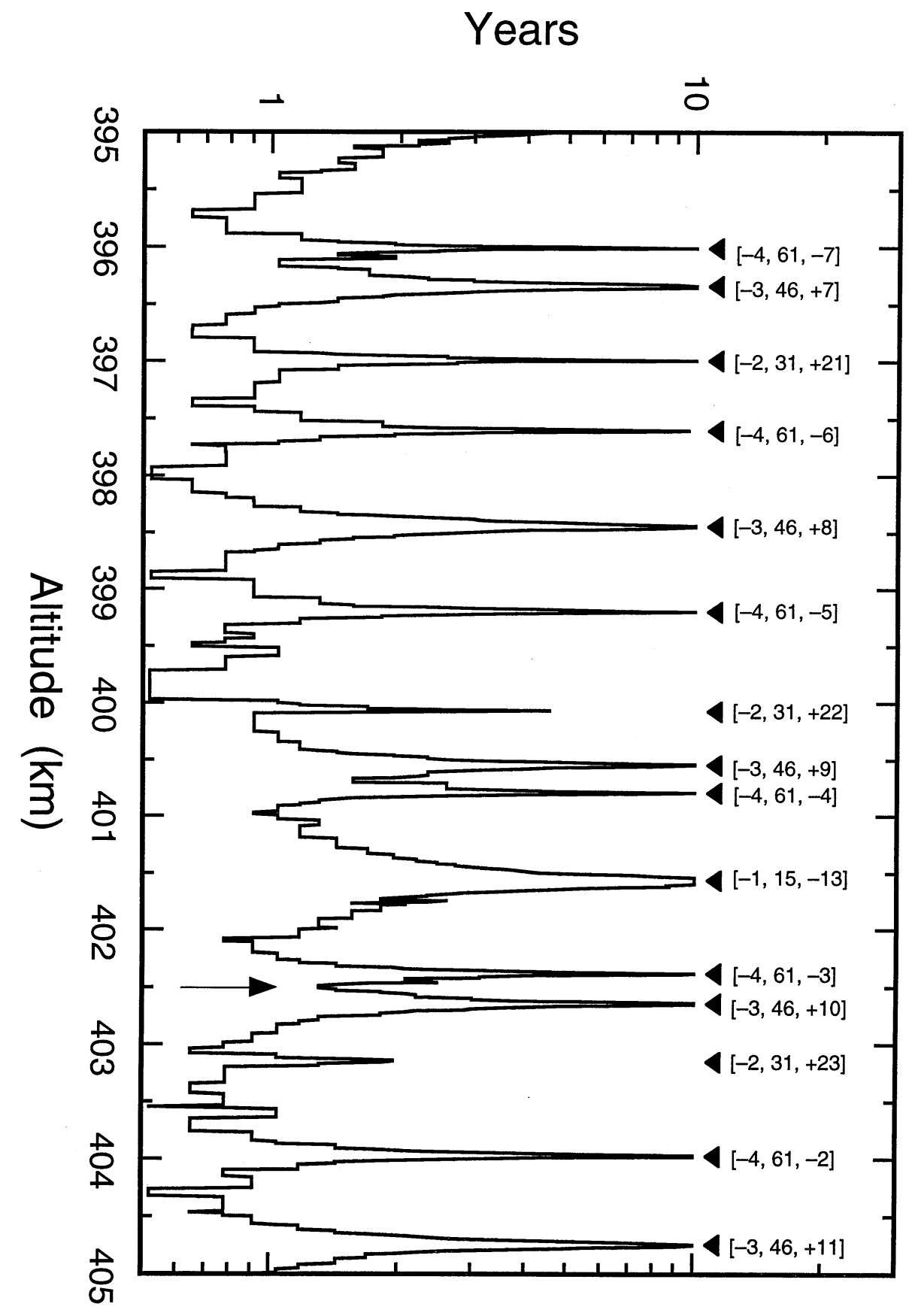


suo!fo^1əsqo to 1әqunN

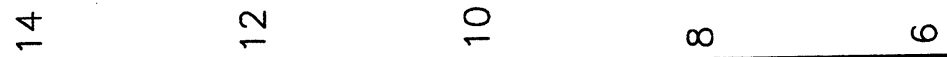

$\checkmark$

N

○

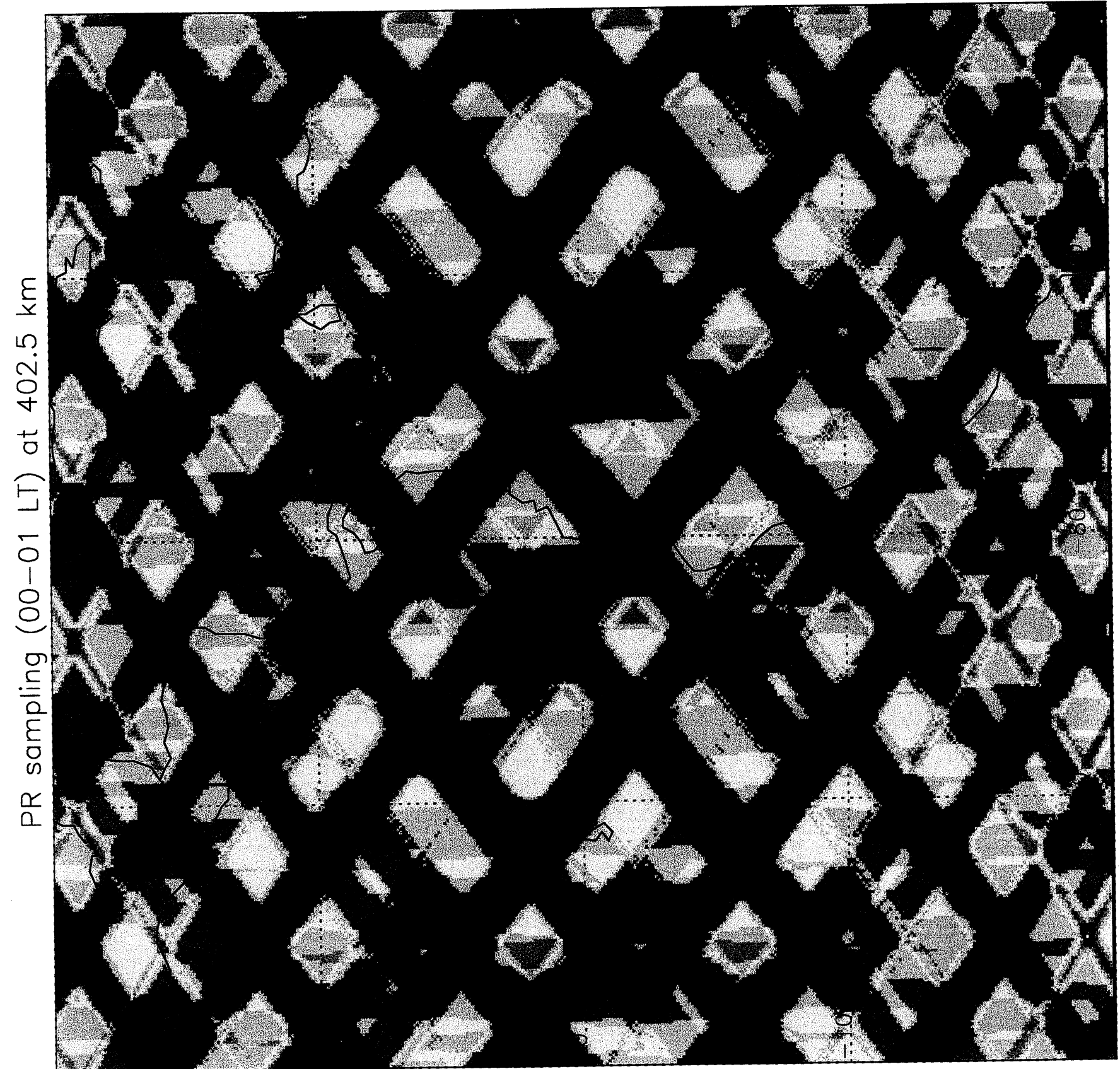




\section{Sampling of the Diurnal Cycle of Precipitation using TRMM \\ Andrew J. Negri ${ }^{1}$, Thomas L. Bell ${ }^{1}$ and Liming $\mathrm{Xu}^{2}$ \\ ${ }^{1}$ Laboratory for Atmospheres, NASA/Goddard Space Flight Center, Greenbelt, MD \\ ${ }^{2}$ Dept. of Hydrology and Water Resources, U. Arizona, Tucson, AZ}

\section{POPULAR SUMMARY}

One of the priority science questions in the design of the Tropical Rainfall Measuring Mission (TRMM) was "What is the diurnal (daily) cycle of tropical rainfall and how does it vary in space?" In order to do this, TRMM's orbit was designed to precess (or make a complete cycle) through the 24 hours of the day during a period of 46 days. The two main instruments aboard the TRMM satellite are the TRMM Microwave Imager (TMI) and Precipitation Radar (PR). These instruments have ground-track widths of $720 \mathrm{~km}$ and 220 $\mathrm{km}$ respectively. The combination of a long precession period and narrow ground-track results in peculiar patterns of sampling (the number of observations of any spot on the earth). This sampling pattern in turn affects our ability to understand the daily variation of the rainfall estimates produced by these two instruments. This study shows that the optimal time period over which to accumulate the rainfall observations is four hours. Over that interval, the spatial variation of the sampling across any tropical region, as well as the sampling error, is minimized. Results are important for our understanding of the hourly variation of rainfall over remote regions such as the Amazon Basin, where conventional observations are not possible. The study verifies its observational results using a simple orbital model, and demonstrates the sensitivity of the sampling pattern to the altitude of the TRMM satellite, important for future missions such as the Global Precipitation Mission. 